OPEN ACCESS

Edited by:

Chiara Martinelli,

Istituto Italiano di Tecnologia, Italy

Reviewed by:

Enza Torino,

University of Naples Federico II, Italy

Matteo Lulli,

University of Florence, Italy

Anna Laurenzana,

University of Florence, Italy

*Correspondence:

Mohammad Hosein Farzaei

mh.farzaei@gmail.com

Mohammad Abdollahi

Mohammad@tums.ac.ir

Specialty section:

This article was submitted to

Nanobiotechnology,

a section of the journal

Frontiers in Bioengineering and

Biotechnology

Received: 02 November 2019

Accepted: 09 March 2020

Published: 07 April 2020

Citation:

Moradi SZ, Momtaz S, Bayrami Z,

Farzaei MH and Abdollahi M (2020)

Nanoformulations of Herbal Extracts

in Treatment of Neurodegenerative

Disorders.

Front. Bioeng. Biotechnol. 8:238.

doi: 10.3389/fbioe.2020.00238

\section{Nanoformulations of Herbal Extracts in Treatment of Neurodegenerative Disorders}

\author{
Seyed Zachariah Moradi, ${ }^{1,2}$, Saeideh Momtaz ${ }^{3,4}$, Zahra Bayrami4, \\ Mohammad Hosein Farzaei ${ }^{1,2 *}$ and Mohammad Abdollahi, ${ }^{4 *}$
}

\begin{abstract}
${ }^{1}$ Pharmaceutical Sciences Research Center, Health Institute, Kermanshah University of Medical Sciences, Kermanshah, Iran, ${ }^{2}$ Medical Biology Research Center, Kermanshah University of Medical Sciences, Kermanshah, Iran, ${ }^{3}$ Medicinal Plants Research Center, Institute of Medicinal Plants, ACECR, Karaj, Iran, ${ }^{4}$ Toxicology and Diseases Group, Pharmaceutical Sciences Research Center (PSRC), The Institute of Pharmaceutical Sciences (TIPS), Tehran University of Medical Sciences, Tehran, Iran, ${ }^{5}$ Department of Toxicology and Pharmacology, School of Pharmacy, Tehran University of Medical Sciences, Tehran, Iran
\end{abstract}

Nanotechnology is one of the methods that influenced human life in different ways and is a substantial approach that assists to overcome the multiple limitations of various diseases, particularly neurodegenerative disorders (NDs). Diverse nanostructures such as polymer nanoparticles, lipid nanoparticles, nanoliposomes, nano-micelles, and carbon nanotubes (CNTs); as well as different vehicle systems including poly lacticco-glycolic acid, lactoferrin, and polybutylcyanoacrylate could significantly increase the effectiveness, reduce the side effects, enhance the stability, and improve the pharmacokinetics of many drugs. NDs belong to a group of annoying and debilitating diseases that involve millions of people worldwide. Previous studies revealed that several nanoformulations from a number of natural products such as curcumin (Cur), quercetin (QC), resveratrol (RSV), piperine (PIP), Ginkgo biloba, and Nigella sativa significantly improved the condition of patients diagnosed with NDs. Drug delivery to the central nervous system (CNS) has several limitations, in which the blood brain barrier (BBB) is the main drawback for treatment of NDs. This review discusses the effects of herbalbased nanoformulations, their advantages and disadvantages, to manage NDs. In summary, we conclude that herbal-based nano systems have promising proficiency in treatment of NDs, either alone or in combination with other drugs.

Keywords: herbal extracts, neurodegenerative disorders, nanoformulations, nanoparticles, Alzheimer's disease, Parkinson's disease

\section{INTRODUCTION}

Neurodegenerative disorders (NDs) are defined as range of disruptions in function or structure of the nervous system or neurons. Such lasting progressive damages may cause disability in thinking, movement, cognition, and memory. Among various NDs, Alzheimer's disease (AD) and other types of dementias; Parkinson's disease (PD) and PD related disorders; Multiple sclerosis (MS); Huntington's disease (HD); and Amyotrophic lateral sclerosis (ALS) are the most prevalent types. Genetic susceptibility, aging, lifestyle, nutrition, chemicals, specific viruses, and exposure to some environmental toxins (Przedborski et al., 2003; Hodjat et al., 2017) are supposed to be predominant 
risk factors of NDs. Nowadays, the global average of life expectancy increased, hence; the prevalence of age-related NDs is drastically rising. According to the World Health Organization (WHO) report on the top 10 causes of global death, the rate of mortality caused by dementia, and age related NDs has raised more than twice from 2000 to 2016, also dementia was the 5th cause of death in 2016 World Health Organization (2018). Thereby, it is predicted that mental and emotional defects will cause emotional, social, and financial burden on the healthcare system in the future World Health Organization (2006). Current treatments for NDs have considerable adverse effects, thus, there is still demand to seek new strategies with reduced harms (Durães et al., 2018). In this respect, natural products sound propitious, although, their penetration through the $\mathrm{BBB}$ is a major obstacle in their delivery to the nervous system (Dwivedi et al., 2019). In this manner, nanotechnology and more specifically, nanomedicine or pharmaceutical nanotechnology provide superior drug delivery systems for NDs management by means of improved monitoring, controlling, constructing, repairing, and diagnosis at a molecular level (Ochekpe et al., 2009; Maravajhala et al., 2012). Nanoformulations of these natural substrates are effective tactics to overcome such problems and can enhance their bioavailability (Ratheesh et al., 2017). This study reviews the recent efforts in the application of nanotechnology in formulation of natural drugs to improve NDs treatment.

\section{NEURODEGENERATIVE DISORDERS (NDS)}

Previously, the CNS disorders were categorized as cognitive, motor, or combined impairments, mainly on the basis of patient's symptoms. This classification faced several criticisms, since some symptoms were common between the groups, also because many symptoms did not fall into a specific category. Today, it has been proven that abnormalities in particular proteins such as amyloid precursor protein (APP), tau, and $\alpha$-synuclein lead to NDs. Currently, the CNS disorders are being reclassified on the basis of the number of protein abnormalities (Rogan and Lippa, 2002).

\section{Alzheimer's Disease (AD)}

Alzheimer's Disease and associated dementia have been listed as the 6th leading cause of death in the United States population (Heron, 2018). According to data published by the $\mathrm{AD}$ association in 2019, 5.8 million of American populations of all ages are living with $\mathrm{AD}$. Age-based population is suffering from $\mathrm{AD}$ and related dementia shown in Figure 1 Alzheimer's and Dementia (2019). AD is a chronic incurable, progressive ND with a long pre-symptomatic period. Generally, AD is associated with cognitive impairments; behavioral, social and work related dysfunctions; and ultimately leads to death (Bateman et al., 2012). Aberrant accumulation of protein $\beta$-amyloid ( $\beta$-amyloid plaques) outside the neurons, and abnormal accumulation of protein tau (tau tangles) inside the neurons are the major hallmarks of AD. The $\beta$-amyloid induces neuronal cell death through disrupting their communications at synapses, while tau tangles contribute to neuronal cell death by blocking the entry of nutrients and

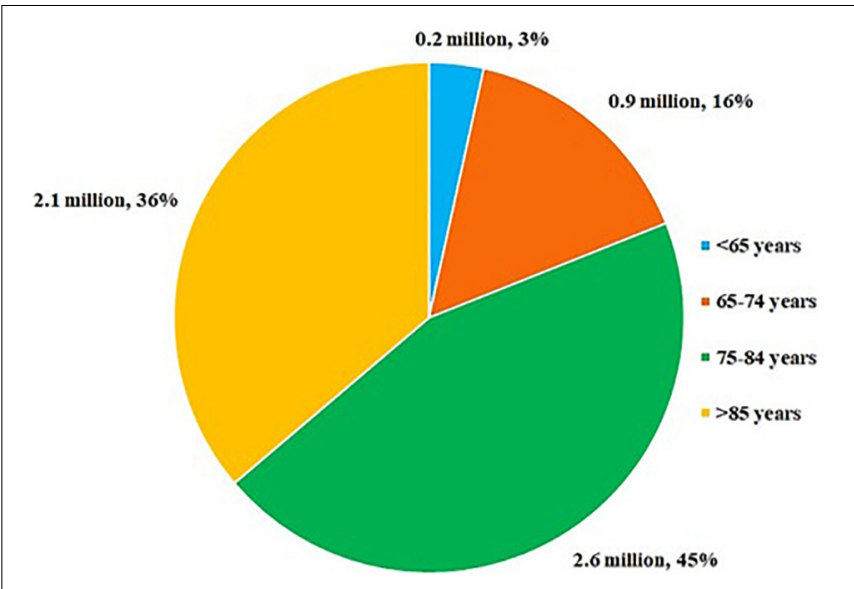

FIGURE 1 | The average age of people with AD.

other essential molecules into the neurons. Gradual increase of $\beta$-amyloid plaques outside the neurons results in consequent spreading of tau tangles throughout neurons (De Paula et al., 2009; Penke et al., 2017; Momtaz et al., 2018).

Aberrant presence of toxic proteins activates the brain immune cells, as well as microglia cells. Microglial cells are specialized brain macrophages that are able to eliminate abnormal aggregated proteins, and debris from dead or dying neurons. Inflammation and atrophy are also associated with AD. Inflammation occurs when microglial cells are not capable of clearing all the things that are supposed to be eliminated, while neuronal loss leads to atrophy.

With time, $\beta$-amyloid plaques and tau tangles spread in other brain areas, which are not involved in cognitive functions (Price et al., 1991). Progressive damages to the brain cells initiate cognitive dysfunctions, and most importantly cause memory impairments (2019). Often, the word 'dementia' is used with $\mathrm{AD}$, as the symptoms of dementia have coincided with the $\mathrm{AD}$ symptoms. Dementia refers to a group of symptoms related to cognitive, and memory decline. Furthermore, abnormal precipitation of protein $\alpha$-synuclein inside the cortical neurons, and Lewy bodies results in dementia (Mckeith et al., 1996; Duda et al., 2000; Rogan and Lippa, 2002).

\section{Parkinson's Disease (PD)}

Parkinson's Disease was reported in the early 18th by the physician Dr. James Parkinson as "shaking palsy". PD is a chronic progressive ND that encompasses both motor- and nonmotor dysfunctions, with deteriorating effects on mobility and muscle control (Demaagd and Philip, 2015). Current global burden of the disease has been more than doubled over the past 26 years, from 2.5 million patients in 1990 to 6.1 million patients in 2016 (Rocca, 2018). The main risk factors of PD include aging, environmental changes, chronic diseases, and social difficulties (Schrag et al., 2015). Continuous loss of dopaminergic neurons in the substantia nigra pars compacta results in loss of dopaminergic function in $\mathrm{PD}$ patients. In PD patients, progressive loss of dopamine in striatum leads 
to increased globus pallidus segment/reticulate portion of the substantia nigra circuit's activity. This activity, consequently, leads to gamma aminobutyric acid (GABA) dysfunction, and inhibition of thalamus and motor activities (Beaulieu and Gainetdinov, 2011). Aberrant accumulation of Lewy bodies is also reported in PD patients (Braak et al., 2003; Del Tredici and Braak, 2012). Mutation in $\alpha$-synuclein gene was shown to form insoluble fibrils in Lewy bodies (Yasuda and Mochizuki, 2010).

\section{Multiple Sclerosis (MS)}

Multiple sclerosis is a chronic neurological disorder, leading to demyelination of the nerve cells in the brain and spinal cord. Such demyelination disrupts interneurons communication, persuading axonal loss in both white and gray matter of the brain and spinal cord, although the loss is more prominent in white matter (Kutzelnigg and Lassmann, 2014). MS is also categorized as an autoimmune disorder, in which T cells target the CNS self-antigen in genetically prone individuals. Initial lesions are mostly formed in focal areas of demyelinated white matter; these focal areas are called plaques. Pathological symptoms of MS vary with the locations of the plaques, but basically are associated with infiltration of immune $\mathrm{T}$ cells across the BBB (Polman et al., 2011). Demyelination and loss of trophic support in oligodendrocytes lead to axonal degeneration (Fünfschilling et al., 2012; Lee et al., 2012). Pathological aggregation of fibronectin was also observed in MS lesions. It was documented that the aggregation of this glycoprotein is likely associated with remyelination failure. In addition, tau protein, amyloid- $\beta$ and amyloid precursor proteins, which are normally detected in $\mathrm{AD}$ and $\mathrm{PD}$ subjects, are also found in plaques and lesions of MS patients (Stoffels et al., 2013; David and Tayebi, 2014). MS subjects experience a series of relapsingremitting courses, in which, there is an acute episode of neural impairments followed by normal baseline function. With time (after 10-15 years), relapses shift into inevitable progressive neurodegeneration, termed as secondary progressive MS (Scalfari et al., 2014). However, approximately $10-15 \%$ of patients directly enter the secondary neurodegenerative state, known as primary progressive MS. The length of the relapsing-remitting state shows considerable variations, however, the rate of neurodegeneration is highly consistent, irrespective of the disease course and severity (Friese et al., 2014).

\section{Amyotrophic Lateral Sclerosis (ALS)}

Amyotrophic lateral sclerosis includes two major forms; sporadic and familial types. The sporadic form (prevalence of 9095\%) has no hereditary history, while the familial type (5$10 \%$ ) has a genetically inherited component (Abhinav et al., 2007; Zarei et al., 2015). ALS is a heterogeneous neurological disorder; characterized by degeneration of both the upper and lower motor neurons (Logroscino et al., 2008, 2010). Besides cellular stress, it was suggested that the aggregation of intraneuronal proteins i.e., TAR DNA-binding protein 43 (TDP-43), superoxide dismutase (SOD1), and fused in sarcoma (FUS) disturb normal protein homeostasis, thereby inducing ALS. These proteins are well identified in pathological studies of patients with ALS and in animal models of the disease
(Morgan and Orrell, 2016). Common symptoms of ALS include muscle tenderness, cramping, twitching, and muscle impairment (Goetz, 2000). Later in the advance stage of the disease, patients experience dysphagia (swallowing difficulty), dysarthria (speech difficulty), and dyspnea (difficulty in breathing) (Kori et al., 2016). Environmental pollutants and diet have also been investigated for their association with ALS (Morozova et al., 2008; Yu et al., 2014). Multidisciplinary approaches seem favorable for ALS management.

\section{Huntington's Disease (HD)}

Huntington's disease is a monogenic autosomal dominant neurological disease. Due to its autosomal dominant inheritance pattern, progressiveness and the combination of motor/cognitive/and behavioral impairments, the disease condition is traumatic to patients and their relatives (Bates et al., 2015). Pathologically, HD is the result of an expanded trinucleotide repeat of CAG sequence in the gene HTT5 on chromosome 4, encoding the abnormal pathogenic multifunctional protein named Huntingtin. Mutant protein holds an unusual polyglutamine sequence, corresponding to the expanded CAG repeat, which is known to be toxic in nature, and results in neuronal cell death or dysfunction. Neurons of the striatum region are particularly prone to this mutant protein; however, HD has been documented as a disorder of whole the brain and body. Abnormality of huntingtin protein leads to neuronal death through several mechanisms including direct effect of the mutant protein exon 1; and tendency of the mutant protein to form aggregates with direct effect on axonal transport, protein homeostasis, and mitochondrial function (Kay et al., 2014; Ross et al., 2014). Losses of the brain-derived neurotrophic factors, glutamate excitotoxicity, and toxic effects of repeat associated non-ATG translation are the other hypothesis involved in neural damage of HD (Bates et al., 2015).

\section{CLINICAL STRATEGIES, MANAGEMENT, CHALLENGES AND LIMITATIONS VERSUS NDS}

Recent couple of decades have witnessed exceptional researches that propelled our knowledge about NDs. Advances in genetic sciences enormously helped to target such diseases with novel technologies (Chen and Pan, 2014). A set of allopathic medicine such as dopaminergic medications for PD and related motor disorders (Mizuno, 2014); cholinesterase inhibitors for treating cognitive disorders (Doody et al., 2009); analgesic drugs for pain (Chaudhuri and Schapira, 2009); anti-inflammatory (Tizabi et al., 2014) and antipsychotic drugs for dementia and other behavioral dysfunctions (Desai and Grossberg, 2005) are used to stop the tremor and refractory movement disorders (Okun, 2014). Active and passive immunotherapies are new hopes for $\mathrm{AD}$ treatment, though, the adverse effects of these antibodies are the biggest concern of immune related drugs (Chen and Pan, 2014). Integrative medicine, including Western and traditional medicine, is also effective option in improving NDs (Pan and Zhou, 2014). For example, in PD patients, utilization of 
"Traditional Chinese Medicine" (TCM) and allopathic medicine helped to improve sleeping and associated non-motor disorders (Pan et al., 2011a,b). Ayurveda also has a history of PD treatment with lower side effects (Lloret et al., 2013). Moreover, TCM was shown to improve the symptoms of cognitive and behavioral impairments in AD subjects (Pan et al., 2014). Medicinal plants used in traditional Persian medicine have also shown notable advantages for NDs treatment (Farzaei et al., 2018b). In another study, a balanced based exercise regimen was shown to improve the postural stability in PD patients (Li et al., 2012). It is believed that combination of integrative medicine and modern science will gradually help to treat degenerative diseases. Despite considerable progressions in NDs management, certain limitations and challenges are yet to be addressed.

It is thought that NDs might be treatable by predicting pathological conditions prior to the onset of the disease, i.e., the biomarkers of human immunodeficiency viruses (HIV) (CD4 cell count or viral load). This idea is supported by the well-definition of pathological and clinical phenomena. In sporadic $\mathrm{PD}$, the severity of the disease is measured by nonspecific markers. For instance, the majority of individuals with constipation will never get PD. Therefore, sorting of individuals to well defined risk groups is still a need that has to be fulfilled. Definition of decent outcomes and efficient biomarkers are necessary to show whether a participant is responding in preclinical and clinical trials.

Systemic delivery of drugs to the CNS is a significant challenge, mainly due to their poor access to the brain, extensive firstpass metabolism, limited half-life, and possible side effects when reaching non-target peripheral tissues (Tonda-Turo et al., 2018). The BBB and other barriers inside the CNS such as the meninges, blood cerebrospinal fluid barrier, choroid plexus within each brain ventricle, and circumventricular organs are the obstacles of drug delivery to the CNS. Hence, development of systemic delivery systems with increased efficacy is essential for the CNS pharmacotherapy.

\section{Medicinal Plants and Their Phytochemicals for NDs Treatment}

Numerous studies tried to characterize phytochemicals with positive effects on the neural system from medicinal, and even dietary plants (Kim et al., 2014; Naoi et al., 2017, 2019). Beneficial effects of neuroprotective phytochemicals are mainly attributed to their antioxidant, and anti-inflammatory properties (Kim et al., 2010). The bioavailability of herbal bioactive components in body is a key point in their bioefficacy, and might be restricted by factors such as fast metabolism, trivial permeability, and the lack of stability within the CNS (Pandareesh et al., 2015). Herein, we list the main chemical groups involved in neuroprotection.

\section{Polyphenols}

Polyphenols are the largest group of plant secondary metabolites, and their structures vary from hydroxyl groups attached to the aromatic ring in the simple phenols to highly complex polymeric compounds in tannins and lignins. Respecting their structures, polyphenols are strong antioxidant, and anti-inflammatory compounds with broad contribution to manage various diseases. To date, several clinical trials were proceeded to investigate the potency of polyphenols on different NDs (Goetz, 2000; Logroscino et al., 2010; Kori et al., 2016; Morgan and Orrell, 2016; Davatgaran-Taghipour et al., 2017). Flavonoids are the major bioactive group of polyphenols with more than 6000 members (Figure 2). Flavones (i.e., apigenin and luteolin) (Patil et al., 2014), flavanol (i.e., epigallocatechin-3-gallate-EGCG) (Singh et al., 2016), flavonols (i.e., QC and kaempferol) (Lagoa et al., 2009; Barreca et al., 2016), isoflavones (i.e., daidzein and genistein) (Qian et al., 2012; Aras et al., 2015), flavanones (i.e., naringenin and hesperetin) (Cirmi et al., 2016), and anthocyanins (i.e., cyanidin and delphinidin) (Strathearn et al., 2014) are the best known flavonoids with considerable medicinal and dietary values, particularly neuroprotective properties.

Curcumin (diarylheptanoid) (Hu et al., 2015), RSV (stilbenoid) (Gomes et al., 2018), catalpol (iridoid glycoside) (Jiang B. et al., 2015), lycopene (carotenoid) (Prema et al., 2015), and smilagenin (saponin) (He et al., 2019) are some of the non-flavonoid polyphenols with significant neuroprotective effects. Phenolic acids containing cinnamic acid derivatives (i.e., p-coumaric acid, caffeic acid, ferulic acid), and the benzoic acid derivatives (i.e., gallic acid, vanillic acid, protocatechuic acid) have been reported to improve neurological dysfunctions through direct effect on neural, and glial cells (Nabavi et al., 2015; Szwajgier et al., 2017; Figure 3). Scavenging of reactive oxygen and nitrogen species, activation of redox-responsible transcription factors, regulation of gene expression, inhibition of $\beta$-amyloid generation and aggregation, as well as regulation of mitochondrial apoptosis system have been introduced as some of the mechanisms involved in the neuroprotective functions of polyphenols. Furthermore, it is suggested that polyphenols can bind to specific receptors on cell surface and trigger different antioxidant signaling pathways (Rehman et al., 2019).

\section{Alkaloids}

Alkaloids are organic natural compounds containing nitrogen in their structures. There are various classifications of alkaloids based on their chemical structures, biochemical precursors, and pharmacokinetics. Heterocyclic alkaloids (typical alkaloids) with nitrogen in their cyclic ring are more common. Berberine (Berberis vulgaris) (Jiang W. et al., 2015), montanine (Rhodophiala bifida) (Pagliosa et al., 2010), morphine (Papaver somniferum) (Wang et al., 2018), salsoline (Salsola oppositifolia), and galantamine (Galanthus nivalis) (Pagliosa et al., 2010) belong to isoquinoline alkaloids, and proven to have positive effects on NDs. In addition, PIP (a piperidine alkaloid from Piper nigrum) (Chonpathompikunlert et al., 2010), geissospermine (Vital et al., 2015) (an indole alkaloid from Geissospermum vellosii), nicotine (Quik et al., 2012) (a pyridine alkaloid from Nicotiana tobaccum), caffeine (a methylxanthine derivative from Coffea arabica) (Tellone et al., 2017), and harmine (an indole $\beta$-carboline from Peganum harmala) (Biradar et al., 2013) were also shown to possess neuroprotective effects. These species majorly belong to Amaryllidaceae, Papaveraceae, Solanaceae, and Ranunculaceae families of plant kingdom. Figure 4 represents the chemical structures of heterocyclic alkaloids. Alkaloids affect NDs through different mechanisms including modulation of neurotransmitter systems, inhibition 


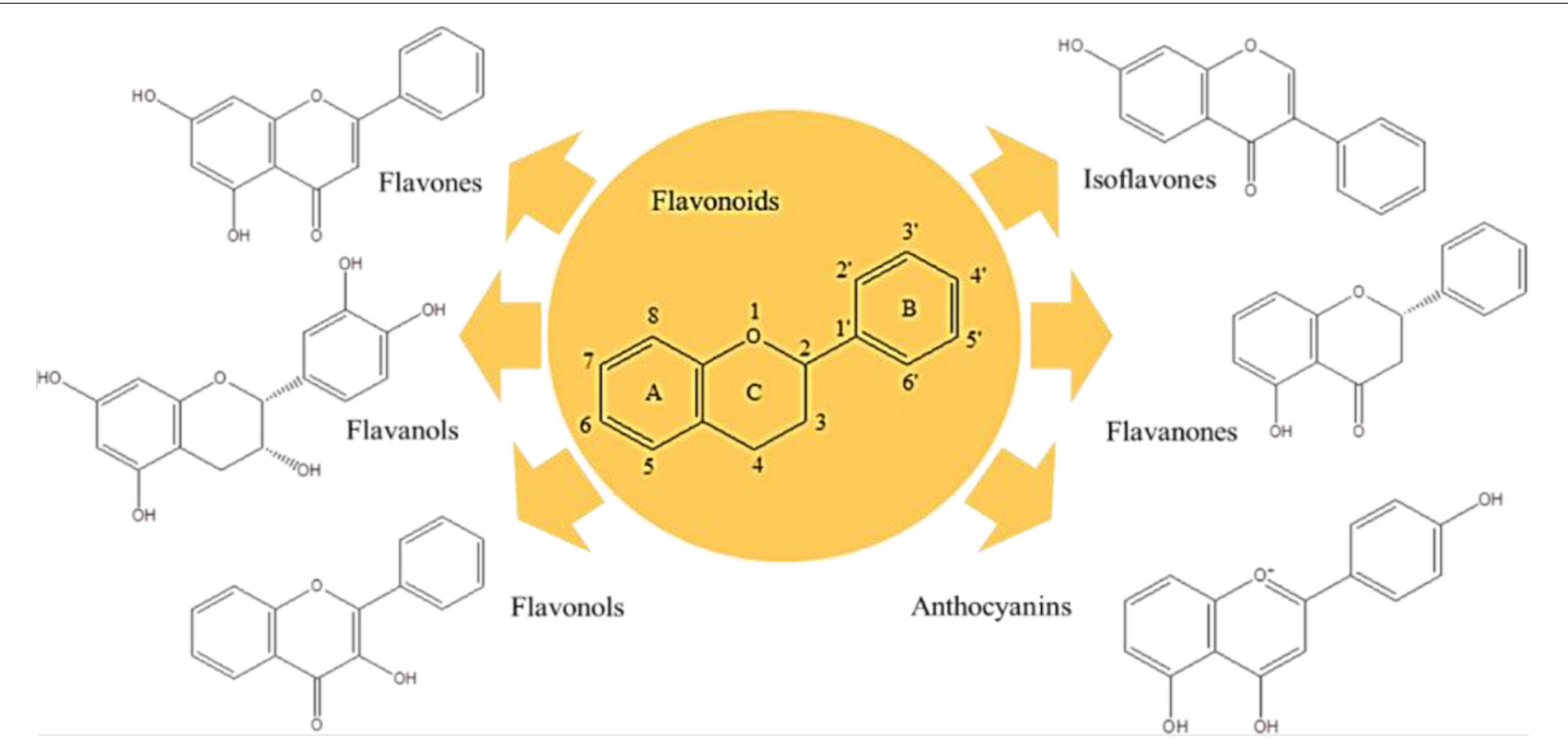

FIGURE 2 | Flavonoids.

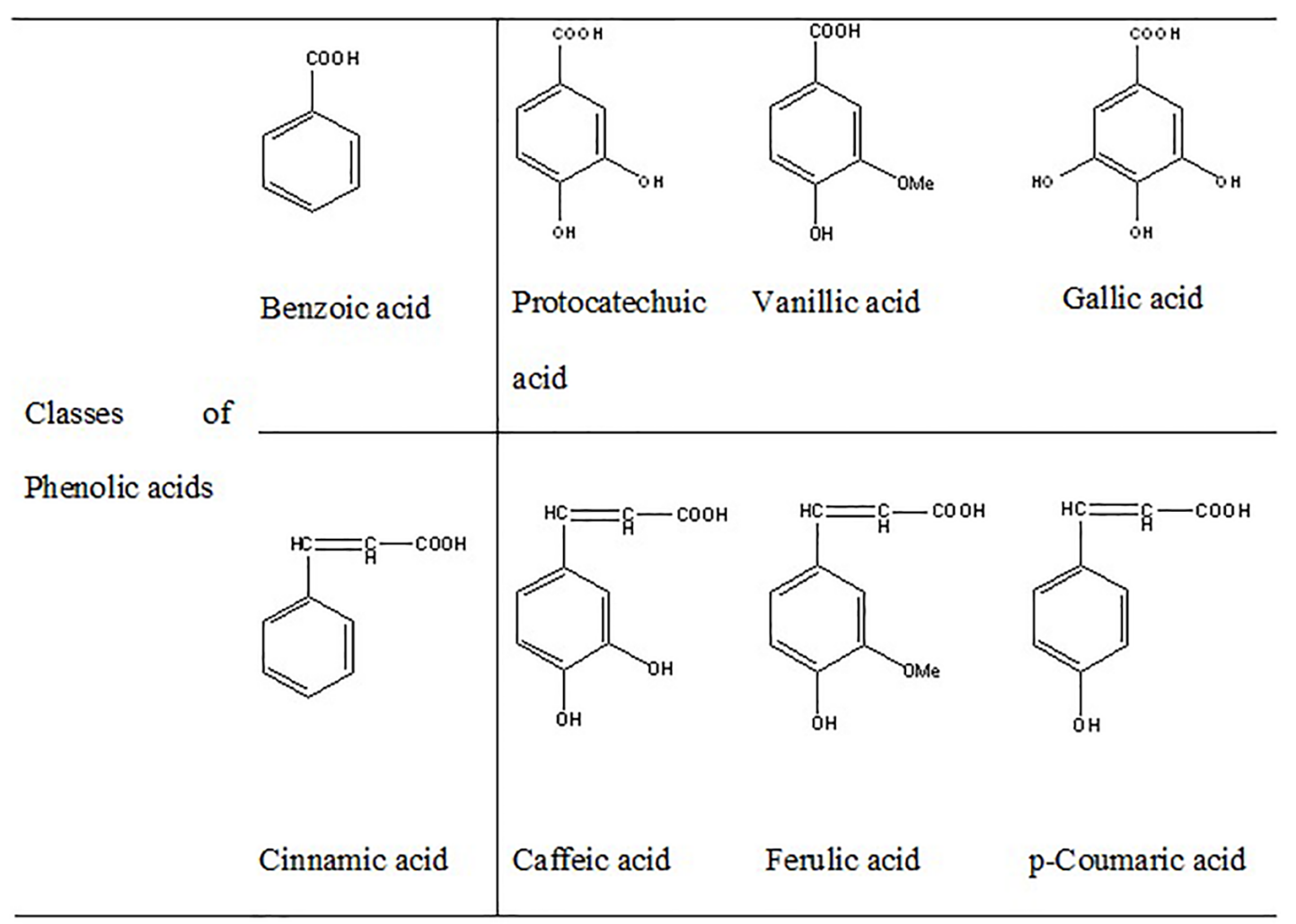

FIGURE 3 | Phenolic acids.

of anti-amyloid and monoamine oxidase (MAO), inhibition of acetylcholinesterase and butyrylcholinesterase, inhibition of $\alpha$-synuclein aggregation, and by anti-inflammatory and antioxidant activities. They also might act as dopaminergic and nicotine agonists or N-methyl-D-aspartate (NMDA) antagonist (Hussain et al., 2018). 


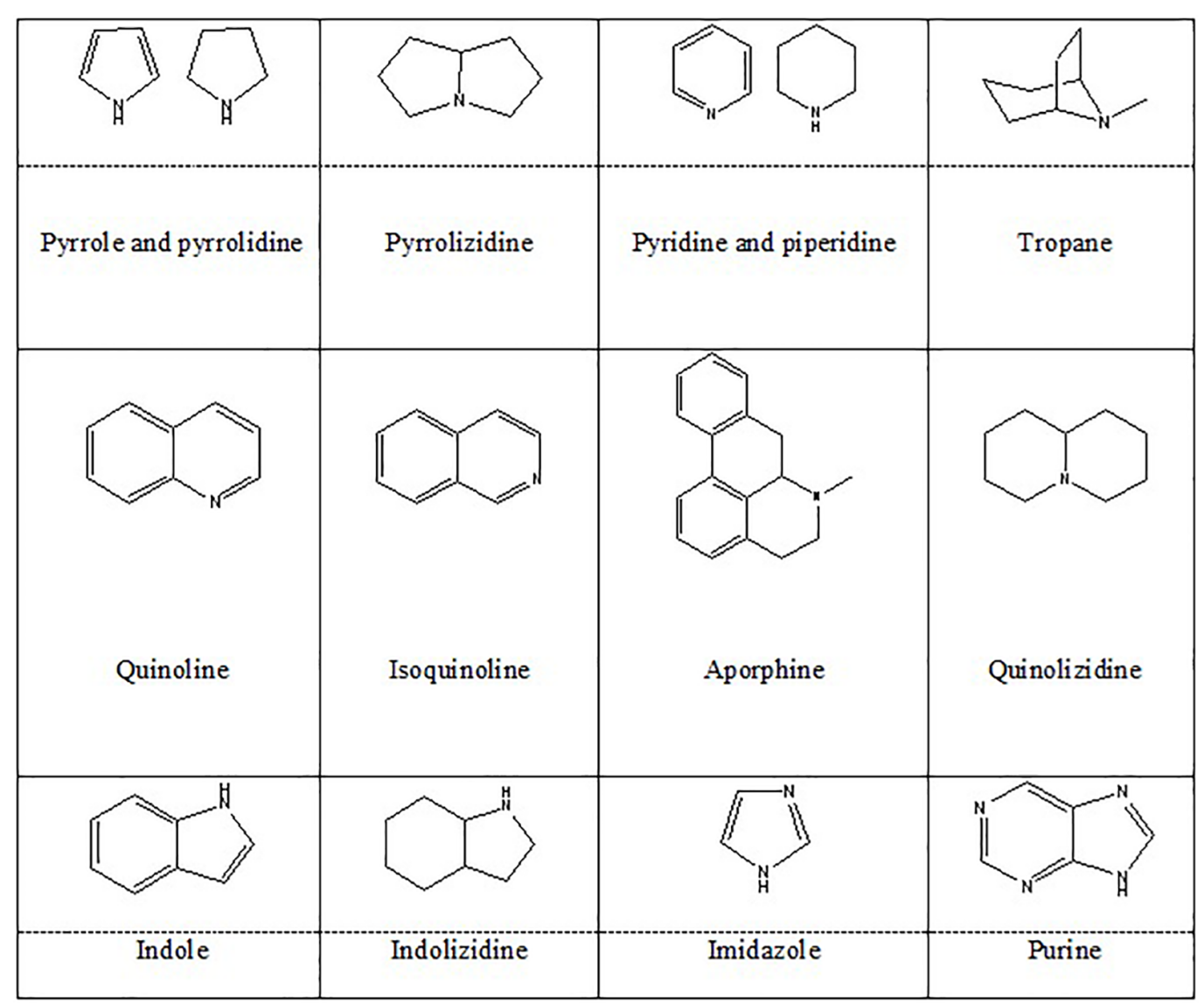

FIGURE 4 | Heterocyclic alkaloids.

\section{Terpenoids}

Terpenoids are unsaturated organic compounds composed of isoprene units. It was shown that G. biloba has positive effects on NDs and contains flavonoid glycosides, organic acids and terpenoids such as ginkgolides A, B, C and bilobalide (Shi et al., 2010). Thymoquinone (TQ), the major component of Nigella sativa is a monoterpene that has been suggested to be responsible for the neuroprotective property of the plant (Khazdair, 2015). Thymol is another neuroprotective monoterpene isolated from Thymus vulgaris (Deng et al., 2015). GABA mediated inhibition of synaptic transmission is the probable mechanism for the thymol neuroprotective effect (Marin et al., 2011).

\section{Advantages of Nanoparticles for Treatment of NDs}

The presence of BBB is the main obstacle for NDs treatment strategies. So far, great efforts have been conducted to dispel this problem with help of various nano methods (Bhaskar et al., 2010). Among the drug delivery carriers that have been engineered, polymeric nanoparticles (PNPs) received particular interests, due to their high drug loading capacity, long circulation halflife, and high capacity to protect the drug against debasement, which offers broad surface handling possibilities for ligands to pass the BBB (Roney et al., 2005). Nowadays, there are claims that NP-based drug delivery systems effectively boost up the passage of drugs through the $\mathrm{BBB}$ and even raise the drug absorption in the brain. Biodegradability and reduced toxicity to peripheral organs are reported as the main advantages of nanomaterials for such therapeutic purposes (Caruso et al., 2011). Nanomaterials pass the BBB through non-invasive, and invasive mechanisms. In invasive manner, physical methods, the BBB is ruptured and nanomaterials are transported across the BBB through paracellular pathways such as intracerebroventricular or intracerebral injection, i.e., intranasal delivery strategy, receptormediated $\mathrm{BBB}$ crossing strategy, cell-mediated $\mathrm{BBB}$ crossing strategy, shuttle peptide-mediated $\mathrm{BBB}$ crossing strategy and cellpenetrating peptide $(\mathrm{CPP})$. In contrast, non-invasive strategies preserve the basic structure of $\mathrm{BBB}$ during the drug delivery process and do not harm the BBB (Xie et al., 2019). Encapsulation inside the nanocarriers simplifies the drug entry into the brain through a non-invasive manner (Poovaiah et al., 2018). It is believed that nanocarriers can be engineered desirably without affecting or altering the medication's properties.

In neural cells, in addition to the $\mathrm{BBB}$, nanomaterials target free radicals production/activity and the oxidative related pathways (Win-Shwe and Fujimaki, 2011); regulate the inflammatory events (i.e., suppression and/or overexpression 
of pro- or inflammatory cytokines and chemokines); possess autophagy modulating (Zheng et al., 2016) and neuronal tissue regeneration effects (Re et al., 2012); also can suppress neural apoptosis or toxicity (Ali et al., 2017); and modulate the transcription, transduction, and intracellular signaling pathways (Kim et al., 2017). In AD subjects, nanostructures display high affinity for $\mathrm{A} \beta$ to reduce its toxic effects, while in PD case, nanobased approaches facilitate dopamine delivery and release to the brain (Re et al., 2012).

Treatment of NDs with NPs may have significant consequences such as proper biocompatibility and biodegradability, improvement of the drug pharmacokinetic and therapeutic efficacy, and reduction of the drug adverse effects (Ratheesh et al., 2017). It was reported that herbal GinsenosideNPs possessed neuroprotective effect, mainly through crossing the BBB (Aalinkeel et al., 2018). Poly Lactic-co-Glycolic Acid (PLGA)-functionalized QC (PLGA@QC)-NPs shown negligible cell toxicity, inhibited the $A \beta_{42}$ fibrillation, and reduced the $\mathrm{A} \beta_{42}$-induced toxicity in human neuroblastoma SH-SY5Y cells in vitro. Novel Object Recognition and Morris Water Maze tests showed that PLGA@QC)-NPs treatment improved learning and memory impairments in AD mice (Sun et al., 2016). Bacoside (a loaded PLGA-NP) (Jose et al., 2014), Cholin-NPs (Li et al., 2011), Lectin-NPs conjugated with Solanum tuberosum lectin (Zhang C. et al., 2014), were also shown beneficial for AD management.

In summary, NPs loaded herbal extracts showed consequential effects on NDs by improving the drug biodegradability and biocompatibility, amelioration of the therapeutic efficacy, removing pharmacokinetics restrictions, reducing side effects, controlling the release, and by in site targeting. Furthermore, some of nanoparticle materials have the extra potential for enhancing the cure efficacy, such as decreasing ROS level, significant antioxidant properties, and even inhibiting the aggregation of $\mathrm{A} \beta$. Although, nanocarriers are powerful tools for delivering specific compounds to the brain and can cross through the $\mathrm{BBB}$ in an easier manner, variant problems remained to be resolved. Smaller size may cause route dislocation, induce blood clots and hemolysis, thereby, creating platelet aggregation (Ramanathan et al., 2018; Niu et al., 2019). Imbalanced distribution of NPs in the brain may cause undeniable potential risks. Inorganic part of nanostructures such as gold, silica, iron, and cerium oxide particles make the metabolism of these NPs obscures.

Accumulation of these compounds in the brain can induce neurotoxicity through their impact on the mitochondrial activity and interference with autophagy, apoptosis, and neuronal inflammation (Niu et al., 2019).

\section{HERBAL MEDICINES AND NATURAL COMPOUNDS NANOFORMULATIONS}

\section{Polymeric Nanoparticles (PNPs), Nanocapsules, and Nanospheres}

Polymeric nanoparticles have high drug loading capacities, enabling the system to protect and support the incorporated drug against degradation. Therefore, there is an increasing chance of drug penetration and access to the brain. Due to their stable structures and unique features, they can evade macrophages, thus, facilitating the drug delivery to the CNS. Nanospheres are dense polymeric matrices that are prepared via micro-emulsion polymerization, while nanocapsules are developed by a thin polymeric envelope surrounding an oil-filled cavity (Modi et al., 2009, 2010; Ganesan et al., 2015).

\section{Polymeric Nanogels and Nanosuspensions}

Nanogels are described as highly crosslinked nano-sized hydrogel systems that are either non-ionic- or ionic- monomers or copolymerized. The size of the nanogels varies from 20 to 200 nanometers. This system has a $40-60 \%$ capacity for drug loading. Previous studies suggested that nanogel structures could enhance the brain uptake and decrease the liver and spleen uptake of oligonucleotides. Drug loaded nanosuspensions are crystalline drug particles that have been stabilized by mixtures of lipids or nonionic surfactants. Nanosuspensions have significant advantages such as their simplicity to use, and their notable capacity for drug loading and delivery (Modi et al., 2010; Jain et al., 2019).

\section{Carbon Nanotubes (CNTs) and Nanofibers}

Inorganic nano-drug delivery systems such as mesoporous silica nanoparticles, CNTs, layered double hydroxides, superparamagnetic iron oxide nanoparticles, and calcium phosphate nanoparticles emerged therapeutic applications in various diseases, particularly NDs. Inorganic nano-carbon systems are able to pass prolonged systemic circulation; while enhancing the drug accumulation, permeability, retention effect, stability, and availability to desire sites. In addition, these nanostructures could modulate the drug release, and facilitate drug imaging, and monitoring its function. Besides, being flexible to various stimuli (i.e., temperature, $\mathrm{pH}$, chemicals, pressure, and magnetic and electric fields) makes the CNTs a great catch for nanopharmacology (Naz et al., 2019).

Utilization of carbon-based nanostructures, like CNTs, is one of the most noteworthy strategies for neurological applications. CNTs are allotropes of carbon with a cylindrical nanostructure. CNTs are being extensively explored to ameliorate their electrical stimulation. One of the effective options for treatment of different psychiatric and neurologic disorders, especially PD, is Deep Brain Stimulation. In some cases, the immune system reacts to the presence of these stimulating electrodes, arising problems for the utilization of such fibers. Fabrication of nanofibers is safer than CNTs, and the risk of air pollution is lower. Interestingly, nanofibers are used to design and produce neural prosthetics. Other nano methods may not be able to accomplish the same applications in comparison with the electrospun nanofibers (Modi et al., 2009, 2010; Ganesan et al., 2015). Considering their electronic properties, structural attributes, and suitable biological effects on the growth and viability of cells; CNTs can be applied as scaffolds alone or blending with 
other biodegradable biomaterials to promote neuro-engineering, for purposes like neuroprotection, neuronal differentiation, regeneration, interface, and stimulation (Xiang et al., 2019).

\section{Polymeric Nanomicelles}

Polymeric micelles are among the most promising delivery systems in nanomedicine. This system has a core-shell structure with a lipophilic core, and a shell composed of hydrophilic polymer blocks. The main advantage of this system is the presence of hydrophobic active ingredients. The size of the polymeric micelles varies from 10 to 100 nanometers (Modi et al., 2009, 2010; Ganesan et al., 2015).

\section{Polymeric Nanoliposomes}

Nanoliposomes are phospholipids with two hydrophobic tails and a hydrophilic head. Their sizes differ from 30 nanometers to few microns. A significant amount of drugs can be incorporated into the lipid bilayers or within the liposome aqueous compartments. Nanoliposomes with modified surfaces can decrease the drug opsonization in plasma, reduce the liver chance to eliminate such as liposomes, and increase their systemic circulation times. In vitro studies proven their efficiency for targeted CNS drug delivery, and confirmed their remarkable abilities to transfer a wide range of drugs from the BBB (Modi et al., 2009, 2010; Ganesan et al., 2015). Figure 5 represents the nanoformulations that are used to improve the effectiveness of natural compounds.

\section{Exosomes: New Promising Nanocarriers}

Exosomes are lipid bilayer enclosed extracellular vesicles with nanometer-size ranging from $30 \mathrm{~nm}$ to $150 \mathrm{~nm}$ and are constructed in the endosomal compartment of the majority of eukaryotic cells such as B and T cells, dendritic cells, and macrophages. Exosomes have several special features that make them extraordinary and distinct from other nanocarriers. High biocompatibility; nanoscopic size; ability to communicate between cells, both systemically and locally; light immunogenicity; having remarkable potential to prevail over

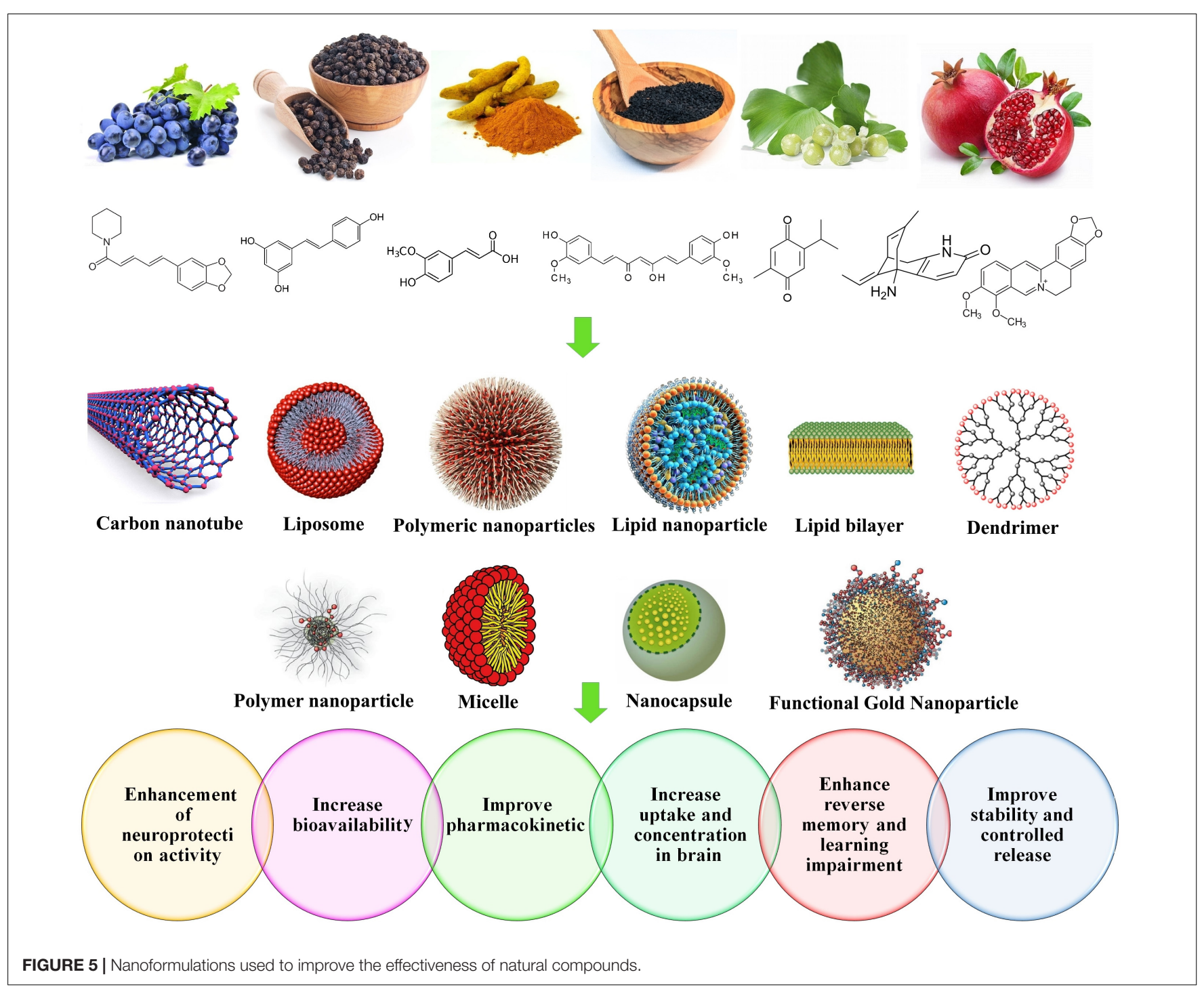


biological barriers; considerable potential for tissue targeting; encapsulation and carrying of various categories of unstable therapeutic molecules such as lipids, hormones, proteins, and genes; have enumerated the exosomes as suitable promising transporters for improving the drug delivery for treatment of multiple disorders such as NDs, cardiomyopathies and cancers (Aryani and Denecke, 2016; Sarko and Mckinney, 2017; Niu et al., 2019; Zhang et al., 2019).

Considering NDs, exosomes can play dual roles by either assisting in spreading the risky proteins such as prions, $\alpha$-synuclein and tau, thereby, accelerating the progression of the disease; or due to their function in transporting cellular entities through the $\mathrm{BBB}$, they can facilitate drug delivery to the brain and reduce the probability of NDs. In addition to the surface localizations of specific proteins, the presence of specific molecules that are known as risk factors for NDs and protecting their contents from degradation, make exosomes proper diagnostic candidates for NDs (Jan et al., 2017).

\section{NANOFORMULATION OF NATURAL PRODUCTS FOR NDS TREATMENT}

\section{Curcumin (Cur)}

Curcumin is one of the most popular and important natural polyphenols derived from Curcuma longa L. Cur has a distinctive chemical structure, making it susceptible to significant effects. Cur affects many biological and pharmacological targets, such as transcription factors, growth factors, genes and cytokines (Bengmark and Nutrition, 2006; Shao-Ling et al., 2009; Guo et al., 2017; Taghipour et al., 2019). Cur can modulate the inflammation process through suppression of several pro- and/or anti-inflammatory mediators such as tumor necrosis factor alpha (TNF- $\alpha$ ), cyclooxygenase-2 (COX-2), and interleukin 8 (IL-8). Moreover, it has been reported that Cur is effective on $A \beta$ and other protein aggregation, making it favorable to improve NDs, primarily AD (Zhang et al., 2010; Hajialyani et al., 2018; Del Prado-Audelo et al., 2019). Despite its impressive therapeutic properties, Cur showed inappropriate pharmacokinetics, in terms of limited absorption, negligible bioavailability, and fast elimination from the body. To overcome such defects, various NPs, nanocapsules, nanomicelles and nanoliposomes were developed to improve the pharmacokinetics and the bioavailability of Cur (Bollimpelli et al., 2016).

\section{In vitro Studies}

Curcumin loaded lactoferrin NPs were developed to protect SK$\mathrm{N}-\mathrm{SH}$ dopaminergic cells from rotenone-induced neurotoxicity, a model that mimics symptoms similar to PD. Besides sustained retention, the intracellular uptake, and the concentration of Cur increased, thereby, enhancing its neuroprotective effects (Bollimpelli et al., 2016). In vitro, a lipid- polyethyleneglycolpolylactide (PEG)-Cur derivative significantly reduced the $A \beta$ aggregation. It was reported that Cur-derivative liposomes and Cur-derivative anti-transferrin antibody liposomes improved the brain penetration of the drug in post-mortem samples of $\mathrm{AD}$ patients (Mourtas et al., 2014). In vitro, nanoliposomes of Cur or Cur derivatives were able to control or decrease the $A \beta$ oligomers or the fibril formation (Taylor et al., 2011). A double-functionalized nanoliposomes of a Cur derivative in modified HIV Trans-activating Transcriptional Activator (TAT) peptide (TATCur-NL) could cross the BBB in vitro and illustrated high affinity for A $\beta$ peptides (Sancini et al., 2013). In another in vitro study, apolipoprotein E3 mediated poly(butyl) cyanoacrylate NPs containing Cur (ApoE3-C-PBCA), enhanced the photostability and the cellular uptake of Cur due to a sustained drug release (Mulik et al., 2010). PLGA coatedCur NPs conjugated with Tet-1 peptide found suitable for treating $\mathrm{AD}$, due to their inhibitory effects on $\mathrm{A} \beta$ formation and the consequent prevention of oxidation and production of free radicals (Mathew et al., 2012). In addition, Cur-decorated nanoliposomes displayed extremely high affinity for $\mathrm{A} \beta_{1-42}$ fibrils (Mourtas et al., 2011). Cur conjugated to a zwitterionic polymer (carboxybetaine methacrylate)-NPs, more effectively inhibited the fibrillation of $\mathrm{A} \beta_{42}$ fibrils than free Cur (Zhao et al., 2018). In another study, Cur-PLGA-NPs induced neurogenesis in neural stem cells through up-regulation of the expression of genes involved in neuronal differentiation and cell proliferation (Tiwari et al., 2013).

\section{In vivo Interventions}

Curcumin encapsulated solid lipid nanoparticles (CSLNs) improved 3-nitropropionic acid (3-NP)-induced HD in rats. CSLNs treated animals showed significant enhancement of the antioxidant enzyme's activities (i.e., SOD and glutathione), while there was a significant decrease in mitochondrial swelling, ROS, protein carbonyls, and lipid peroxidation (Sandhir et al., 2014). Cur-selenium-PLGA nanospheres were shown more efficient in AD mice in comparison with only treated seleniumNPs animals (Huo et al., 2019). In another study, a dual drug-loaded lipid-based nanoformulation (Cur and PIP) found effective on PD. This effect was linked to the suppression of $\alpha$-synuclein aggregation, enhancement of Cur bioavailability, alleviation of oxidative stress, more efficient removal of defective proteins, and acceleration of anti-apoptotic events compared with non-formulated drugs (Kundu et al., 2016). In another study, Cur NPs designed as vectors. These Cur-vectors showed considerable affinities toward $\mathrm{A} \beta_{1-42}$ fibrils and exhibited proper stability/integrity for in vivo applications (Mourtas et al., 2011). In mouse Tg2576 AD model, encapsulated PEG-PLACur improved memory cue compared with control samples, also working memory was more improved in PEG-PLA-Cur treated mice than the ordinary Cur treated group (Cheng et al., 2013). In addition, solid lipid nanoparticles of Cur (CurSLNs) exhibited neuroprotective effects in aluminum-induced behavioral, biochemical and histopathological alterations in the mice brain (Kakkar and Kaur, 2011). Cur-loaded lipidcore nanocapsules (Cur-LNC) improved neuroinflammation, behavioral impairments and reduced the hyperphosphorylation of tau and $\mathrm{A} \beta$ in $\mathrm{AD}$ subjects, compared with free Cur treated animals (Hoppe et al., 2013). The safety and efficacy of a micelle nano-Cur system was reported in patients with ALS. The system increased the probability of survival in patients with ALS as an additional treatment, particularly in those with bulbar 
symptoms (Ahmadi et al., 2018). Encapsulated Cur in chitosanalginate-sodium tripolyphosphate nanoparticles (CS-ALGSTPP NPs) augmented the bioavailability and the half-life of Cur in animal model of MS. Cur-loaded NPs reduced the inflammation, glial activation, and the extent of demyelination areas (Naeimi et al., 2018). In animal model of MS, dendrosome NPs of Cur ameliorated the score of the disease and demyelination, whereas the remyelination was improved, resulting in reduced inflammation and oxidative stress (Mohajeri et al., 2015). Another liposomal mucoadhesive drug delivery system has been shown effective on Cur delivery via nasal route. The system enhanced the drug bioavailability, distribution and stability, also controlled the release characteristics compared with the drug solution alone (Samudre et al., 2015).

In another study, Cur loaded to a low-density lipoprotein (LDL)-mimic nanostructured lipid carrier (Lf-mNLC) that was amended with lactoferrin. Administration of Lf-mNLC to AD animals enhanced the concentration of Cur in the brain and significantly increased its bioavailability, indicating that LfmNLC remarkably controlled the AD progression and symptoms (Meng et al., 2015). It was reported that a type of nano-Cur showed beneficial effects in restoring the expression patterns of dysregulated miRNAs in MS patients (Dolati et al., 2018a). In MS subjects, this system repressed the expression levels of T-helper 17 (Th17) cells, IL-17, and Retinoic acid-related orphan receptor gamma t (ROR $\gamma \mathrm{t})$, demonstrating that this nano-Cur structure can prompt the regulation of dysregulated Th17 cells in MS patients (Dolati et al., 2018a). In another study, the effect of a nano-Cur system on regulatory $\mathrm{T}$-cells frequency and function were investigated in 50 patients with relapsing-remitting MS. The system diminished the expression of forkhead box P3 (FOXP3) and the levels of IL-10, and transforming growth factor beta (TGF- $\beta$ ). In addition, the proportions of peripheral Treg cells were frequency declined, proposing that such nano-system is a competent agent to restore the frequency and function of Treg cells, which play an important role in MS patients (Dolati et al., 2019). Similarly, the very same nano-Cur decreased the expression levels of inflammatory miRNAs, signal transducer and the activator of transcription 1 (STAT1), nuclear factor$\kappa \mathrm{B}(\mathrm{NF}-\kappa \mathrm{B})$, and activator protein 1 (AP-1), while enhancing the expression of STAT5 mRNA (Dolati et al., 2018b). In vivo aggregation of $A \beta_{1-16}$ was diminished using a gold nanoparticlepolyvinylpyrrolidone-Cur conjugate (Brahmkhatri et al., 2018). A Cur-loaded polysorbate 80 (PS80)-modified cerasome NPs caused longer circulation lifetime, and significantly improved the pharmacokinetic properties of the drug than free Cur in PD model (Nisi Zhang et al., 2018). A summary of Cur nanoformulations is provided in Table 1.

\section{Quercetin (QC)}

Quercetin is a bioflavonoid found in diverse fruits, vegetables, and a number of herbal origin oils with well-known neuroprotective, and anti-inflammatory effects. Besides, QC has considerable potency to scavenge ROS. Despite its beneficial effects, poor solubility and low bioavailability hindered its clinical applications. Accordingly, to control such limitations, alternative QC formulations such as nanocapsules, nanogels, liposomes, nanosuspensions, and microsphere have been recommended, in which QC-nanocapsulation was shown to be the most proper form (Chakraborty et al., 2012; Nathiya et al., 2014; Ghaffari et al., 2018). In a study, QC-loaded nano lipidic carriers (NLCs) improved the QC bioavailability and delivery to the brain, while enhanced its antioxidant activity (Kumar et al., 2016).

In PD-like rats, the bioavailability and the efficacy of QC nanocrystals were greater than QC alone. A significant enhancement of the antioxidant enzyme activities and total glutathione level, as well as decline in malondialdehyde level were evident in hippocampal area (Ghaffari et al., 2018). Nanoencapsulated QC improved the ischemia reperfusion induced neuronal damage in vivo, probably in association with enhanced neuronal count and elevated antioxidant activity (Ghosh et al., 2013). In vitro, QC-SLNs significantly ameliorated aluminum induced neurotoxicity. In addition, this system caused meaningful improvement in behavioral and memory retention in animal models of dementia and $\mathrm{AD}$ (Dhawan et al., 2011). An ApoE-QC-RA-PA liposome structure (QCand RA-loaded liposome with conjugated phosphatidic acid and grafted apolipoprotein $\mathrm{E}$ ) was shown to cross the $\mathrm{BBB}$ and to recover the neurotoxicity of $\mathrm{A} \beta_{1-42}$ in $\mathrm{AD}$ model. In vivo $\mathrm{AD}$ model, the same system reduced the lipid peroxidation level, acetylcholinesterase activity and the formation of $\mathrm{A} \beta$ plaques (Kuo et al., 2018). Nasal administration of QC liposomes decreased the degeneration and destruction of cholinergic neurons in the hippocampus of $\mathrm{AD}$ animal model through reduction of oxidative stress (Phachonpai et al., 2010). In another study, a nanoformulation of QC (nano encapsulated QC) was designed and examined on neuronal model of oxidative stress injury. The neuroprotective activity of encapsulated QC was more explicit in comparison with free QC treated animals (Aluani et al., 2017).

The mitochondria delivery of QC increased by QC loaded in PLGA nanocapsules containing dodecyl triphenylphosphonium bromide (TPP + ) as one of the matrix portions (N1QC) structure in the cerebral ischemia reperfusion induced model. N1QC showed higher brain uptake, and significant bioavailability and mitochondrial localization after cerebral ischemia-reperfusion (Ghosh et al., 2017).

\section{Resveratrol (RSV)}

Resveratrol $\left(3,5,4^{\prime}\right.$-trihydroxy-stilbene) is a natural phytoalexin polyphenolic agent from the stilbene-class of compounds. Rapid metabolism, poor water solubility and low bioavailability are the main drawbacks of RSV (Farzaei et al., 2018a; Min et al., 2018). In PD mouse model, RSV loaded on PS80-coated poly(lactide) NPs increased the neuroprotective properties of the drug against 1-methyl-4-phenyl-1,2,3,6-tetrahydropyridine (MPTP)-induced behavioral and neurochemical variation (Da Rocha Lindner et al., 2015). An optimized RSV-loaded lipid-core NPs (RSVLNC) modulated the $A \beta$-triggered neuroinflammation in vitro (Frozza et al., 2013a). Furthermore, RSV-LNC restored the destructive effects of $A \beta_{1-42}$ in rats (Frozza et al., 2013b). In another study, RSV loaded mesoporous nano-selenium (MSeRes/Fc- $\beta$-CD/Bor) delivery system inhibited the $A \beta$ aggregation, decreased oxidative stress, and improved memory impairments 
TABLE 1 | Summary of Cur nanoformulations and their beneficial effects.

\begin{tabular}{|c|c|c|c|}
\hline Nano vehicle/method & Disease & Results & References \\
\hline Lactoferrin nanoparticles & $\begin{array}{l}\text { Brain targeting, neuroprotection } \\
\text { activity }\end{array}$ & $\begin{array}{l}\text { Increase of intracellular drug uptake and higher } \\
\text { neuroprotection properties }\end{array}$ & Bollimpelli et al., 2016 \\
\hline Multifunctional liposomes & $A D$ & $\begin{array}{l}\text { Decrease of } A \beta_{1-42} \text { aggregation and improve of } \\
\text { pharmacokinetics of Cur }\end{array}$ & Mourtas et al., 2014 \\
\hline Liposomes & $A D$ & Decrease of $A \beta$ fibrils formation & Taylor et al., 2011 \\
\hline TAT & $A D$ & $\begin{array}{l}\text { High affinity for } A \beta \text { peptide and increase of Cur } \\
\text { bioavailability }\end{array}$ & Sancini et al., 2013 \\
\hline $\begin{array}{l}\text { Apolipoprotein E3 mediated poly(butyl) } \\
\text { cyanoacrylate }\end{array}$ & $A D$ & Increase of Cur bioavailability and photostability & Mulik et al., 2010 \\
\hline Se-PLGA nanospheres & $A D$ & Reduction of amyloid- $\beta$ aggregation & Huo et al., 2019 \\
\hline PLGA-based NPs & $A D$ & Increase of Cur bioavailability and efficacy & Mathew et al., 2012 \\
\hline Nanoliposomes & $A D$ & High affinity for $A \beta_{1-42}$ fibrils & Mourtas et al., 2011 \\
\hline $\begin{array}{l}\text { Poly(carboxybetaine methacrylate) } \\
\text { (pCB) }\end{array}$ & $A D$ & $\begin{array}{l}\text { Improve of pharmacokinetics of Cur. Inhibition of } A \beta_{42} \\
\text { fibrillation }\end{array}$ & Zhao et al., 2018 \\
\hline Lipid-based NPs & $\mathrm{PD}$ & $\begin{array}{l}\text { Increase of bioavailability and reduce the aggregation of } \\
\text { alpha-synuclein fibrils }\end{array}$ & Kundu et al., 2016 \\
\hline Liposomes & $A D$ & $\begin{array}{l}\text { Increase of affinity for } A \beta_{1-42} \text { fibrils and improve of } \\
\text { pharmacokinetics quality }\end{array}$ & Mourtas et al., 2011 \\
\hline $\begin{array}{l}\text { Polyethyleneglycol-polylactide } \\
\text { (PEG-PLA) }\end{array}$ & $A D$ & Increase of Cur bioavailability & Cheng et al., 2013 \\
\hline CSLNs & $\mathrm{HD}$ & $\begin{array}{l}\text { Reduction of mitochondrial swelling, ROS, lipid peroxidation } \\
\text { and protein carbonyls }\end{array}$ & Sandhir et al., 2014 \\
\hline SLNs & $A D$ & $\begin{array}{l}\text { Recuperation the noxious neurodegenerative effects of } \\
\text { aluminum chloride }\end{array}$ & Kakkar and Kaur, 2011 \\
\hline Lipid-core nanocapsules & $A D$ & Increase of Cur bioavailability & Hoppe et al., 2013 \\
\hline Micelle & ALS & Improve of probability of survival & Ahmadi et al., 2018 \\
\hline CS-ALGSTPP NPS & MS & $\begin{array}{l}\text { Increase of Cur bioavailability, circulation and durability, } \\
\text { inhibition of demyelination Preserve myelinated axons } \\
\text { through amelioration }\end{array}$ & Naeimi et al., 2018 \\
\hline Dendrosome nanoparticles & MS & $\begin{array}{l}\text { Improve of remyelination, decrease of inflammation and } \\
\text { oxidative stress }\end{array}$ & Mohajeri et al., 2015 \\
\hline Mucoadhesive Liposome & $A D$ & $\begin{array}{l}\text { Good stability, controlled release, higher drug distribution } \\
\text { and bioavailability }\end{array}$ & Samudre et al., 2015 \\
\hline Lactoferrin & $A D$ & Improve the bioavailability and increase of brain penetration & Meng et al., 2015 \\
\hline Nano-micelle & MS & Restore the expression pattern of dysregulated miRNAs & Dolati et al., 2018a \\
\hline Nano-micelle & MS & Decrease in Th17 & Dolati et al., 2018a \\
\hline Nano-micelle & MS & $\begin{array}{l}\text { Suppression of Treg cell, IL-10, TGF- } \beta \text {, and FoxP3 } \\
\text { expression }\end{array}$ & Dolati et al., 2019 \\
\hline Nano-micelle & MS & $\begin{array}{l}\text { Suppression of inflammatory miRNAs, STAT1, NF- } \mathrm{B} \text {, and } \\
\text { AP-1; increase the expression of STAT5 mRNA. }\end{array}$ & Dolati et al., 2018b \\
\hline Gold nanoparticle-PVP & $A D$ & $\begin{array}{l}\text { Inhibit the } A \beta_{1-16} \text { aggregation and dissolve the formed } \\
\text { aggregates }\end{array}$ & Brahmkhatri et al., 2018 \\
\hline PS80 modified cerasome & PD & Improve of pharmacokinetic profile & Nisi Zhang et al., 2018 \\
\hline PLGA & $A D$ & $\begin{array}{l}\text { Improve neuronal cell proliferation and differentiation, } \\
\text { recuperation memory and learning disability }\end{array}$ & Tiwari et al., 2013 \\
\hline
\end{tabular}

(Sun et al., 2019). Similarly, RSV-loaded polymeric micelles inhibited the $\mathrm{A} \beta$-induced damages via reducing oxidative stress and apoptosis in vitro (Lu et al., 2009). Vitamin E loaded RSV nanoemulsion showed notable positive effects in PD animal model and a higher concentration of RSV was detected in the brain in comparison with free drug treated group (Pangeni et al., 2014). In another study, RSV-loaded SLNs functionalized with apolipoprotein E, enhanced the bioavailability, concentration and the penetration of the drug in the brain (Neves et al., 2016). Chitosan-coated PLGA NPs of RSV reduced the level of inflammatory cytokines, elevated the IL-10 level, improved neuroprotection and enhanced the functional recuperation, following spinal cord damage in rats (Wang et al., 2019).

\section{Piperine (PIP)}

Piperine (1-piperoylpiperidine) is a pungent alkaloid existing in the fruits of piper species. Bulk of evidence confirmed the effectiveness of PIP on the CNS, which is mainly implicated with the special consequences of PIP on acetylcholine. The $\log P$-value of PIP is 2.25 , making this compound very 
lipophilic, with slight aqueous solubility. In addition, PIP has insufficient oral bioavailability (Elnaggar et al., 2015b; Etman et al., 2018). A research group designed a Tween-modified monoolein cubosomes (T-cubs) loaded by PIP. In AD model, PIP-loaded cubs demonstrated higher efficacy over free drug and were able to restore the cognitive function in studied animals (Elnaggar et al., 2015b). Likewise, PIP microemulsion displayed higher efficacy, better therapeutic outcomes and increased the delivery of PIP to the brain compared with free drug in AD subjects (Etman et al., 2018). Intranasal PIPloaded chitosan nanoparticles showed more efficacy with lower piperine dosage than piperine alone in $\mathrm{AD}$ model (Elnaggar et al., 2015a). In another study, nanoformulations of EGCG alone or in combination with PIP, improved cognitive behavior and reduced the brain acetylcholinesterase level in scopolamineinduced amnesia animals (Dahiya et al., 2018). PIP-SLNs formulated via emulsification solvent diffusion method coated with PS80, diminished the SOD1 level and immobility, while increasing the acetylcholinesterase level. Furthermore, reduced plaques and tangles in histopathological evaluation was evident (Yusuf et al., 2013).

\section{Gallic Acid (GA) and \\ Epigallocatechin-3-Gallate (EGCG)}

Gallic acid is a natural phenolic antioxidant synthesized from 3-dehydroshikimate. GA is suggested to play a protective role against $\alpha$-synuclein and $\beta$-amyloid aggregations, both in vitro and in vivo (Nagpal et al., 2013; Jayamani and Shanmugam, 2014; Mohammad-Beigi et al., 2016). EGCG, is an ester of GA and epigallocatechin, the predominant catechin in tea. Regarding their antioxidant potencies, these compounds may have beneficial effects on NDs by their interactions with important proteins like $\alpha$-synuclein, $A \beta$, huntingtin and transthyretin. GA loaded onto polyethyleneimine-coated human serum albumin nanoparticles (PEI-HSA-GA NPs) was shown to inhibit $\alpha$-synuclein fibrillation in a PD model (Mohammad-Beigi et al., 2016). In another study, GA-loaded chitosan nanoparticles (GANP) recuperated scopolamine-induced amnesia in vivo. This effect was mainly ascribed to GA cholinergic function and its antioxidant properties. Furthermore, GANP coated with Tween 80 (cGANP) reinforced the above-mentioned effects of GA (Nagpal et al., 2013). Nanolipidic EGCG improved the bioavailability and neuronal $\alpha$-secretase activity of EGCG in AD and HIV-associated dementia mouse models (Smith et al., 2010). To decrease the cytotoxicity of EGCG at high doses, EGCG was coupled on to the surface of selenium NPs coated with Tet-1 peptide (Tet1-EGCG@Se). This system inhibited the A $\beta$ fibrillation and disaggregated the $A \beta$ fibrils into the non-toxic compounds (Zhang J. et al., 2014).

\section{Ferulic Acid (FA)}

Ferulic acid is a cinnamic acid derivative with strong antioxidant activity. The compound can reduce the $A \beta$ fibrils formation, thus may affect AD (Picone et al., 2009; Mhillaj et al., 2018). The pharmacokinetics and bioavailability of FA were found to be insufficient, thereby, restricting its therapeutic applications (Trombino et al., 2013). It was shown that the pharmacokinetic and delivery profile of FA was enhanced by SLNs system. In rat brain microsomes, FA-SLNs recovered cell viability and mitochondrial membrane potential, inhibited $\mathrm{A} \beta$-induced cell death, decreased ROS production, and reduced the activation of the apoptosis pathway. Two formulations of FA, SLNs-SA-FA (stearic acid) and SLNs-SF-FA (stearyl ferulate) based solid lipid NPs, were developed with more lipophilic properties than free FA. In addition to bioavailability, the antioxidant effect of FA in the rat brain was increased (Trombino et al., 2013). FA was also entrapped into multiple SLNs, and nanostructured lipid carriers (NLCs). In vitro AD model, ROS production decreased in human neuroblastoma LAN-5 cells treated with FA-loaded SLN, representative of higher protective activity of FA-nanoformulation in neurons than free FA (Bondi et al., 2009). In another investigation, FA-NLCs improved the pharmacological properties of FA via activation of phosphoinositide 3-kinases (PI3Ks) pathway in ischemic neural injuries model (Hassanzadeh et al., 2018).

\section{Plant-Mediated Nano Systems}

Trimethylated chitosan-conjugated PLGA NPs (TMC/PLGANP) loaded with 6-coumarin and coenzyme Q10 improved memory impairment and reduced the senile plaques in transgenic mice. Moreover, it was shown that 6-coumarin loaded TMC/PLGA-NPs were highly accumulated in different parts of the brain in CD-1 mice, following intravenous injection (Wang et al., 2010). Intranasal delivery of Huperzine A (HupA)loaded PLGA NPs (their surfaces were modified with lactoferrinconjugated N-trimethylated chitosan) showed that Lf-TMC NPs facilitated the distribution of HupA in the brain. Furthermore, cellular uptake experiments demonstrated that accumulation of Lf-TMC NPs was higher than nontargeted analogs in SH-SY5Y and 16HBE cells. HupA-PLGA-NPs improved the bioavailability and targeting ability of the drug (Meng et al., 2018). In AD rat model, berberine (BRB)-loaded multiwalled carbon nanotubes (MWCNTs) coated with phospholipid and polysorbate, remanded the memory impairment and reduced the $\beta$-amyloid induced-AD compared with its free form (Lohan et al., 2017). In AD animals, hesperetin nanocrystal retrieved memory consolidation by upregulation of the antioxidant enzymes and glutathione levels (Kheradmand et al., 2018). PEG-based nanospheres encapsulated with vitamin $\mathrm{E}$ increased the antioxidant efficacy of vitamin $E$ against $A \beta$-induced ROS (Shea et al., 2005). Retinoic acid-loaded polymeric NPs exhibited neuroprotective effects on dopaminergic neurons in mouse model of PD. This formulation significantly reduced dopaminergic neuron loss in the substantia nigra, while the expressions of transcription factors Pitx3 and Nurr1 were increased (Esteves et al., 2015). In $\mathrm{A} \beta_{25-35}$ induced oxidative stress in rat hippocampal region, chrysin loaded SLNs showed potent free radical scavenging effect, decreased neuronal damage and improved oral bioavailability; also slight memory retention in behavioral tasks was observed (Vedagiri and Thangarajan, 2016).

Sialic acid (SA)-modified selenium NPs coated with peptideB6 (B6-SA-SeNPs) enhanced the penetration of the drug across the $\mathrm{BBB}$, effectively disaggregated the $\mathrm{A} \beta$ fibrils and 
TABLE 2 | Natural-based nanoformulations and their implications for NDs.

\begin{tabular}{|c|c|c|c|c|}
\hline Component & Nano vehicle / method & Disease model & Results & References \\
\hline Coenzyme Q10 6-coumarin & $\begin{array}{l}\text { Trimethylated } \\
\text { chitosan-conjugated PLGA } \\
\text { nanoparticle }\end{array}$ & $A D$ & $\begin{array}{l}\downarrow \text { Senile plaques } \downarrow \text { Memory } \\
\text { impairment, } \uparrow \text { bioavailability }\end{array}$ & Wang et al., 2010 \\
\hline HupA & $\begin{array}{l}\text { lactoferrin-conjugated } \\
\text { N-trimethylated chitosan } \\
\text { nanoparticles (Lf-TMC NPs) }\end{array}$ & $A D$ & $\begin{array}{l}\text { Appropriate sustained-release, } \uparrow \\
\text { bioavailability, } \uparrow \text { targeting ability }\end{array}$ & Meng et al., 2018 \\
\hline Berberine & $\begin{array}{l}\text { MWCNTs coated with } \\
\text { phospholipid and polysorbate }\end{array}$ & $A D$ & $\begin{array}{l}\text { Remanded the memory impairment } \\
\text { and quelled AChEl activity }\end{array}$ & Lohan et al., 2017 \\
\hline Hesperetin & Nanocrystal & $A D$ & $\begin{array}{l}\text { Improve derecognition of memory } \\
\text { consolidation } \uparrow \text { Activity of } \\
\text { antioxidant enzymes }\end{array}$ & Kheradmand et al., 2018 \\
\hline Vitamin E & PEG-based nanospheres & $A D$ & $\uparrow$ Antioxidant efficacy of vitamin $\mathrm{E}$ & Shea et al., 2005 \\
\hline Retinoic acid (RA) & PNPs & PD & $\begin{array}{l}\text { Significant neuroprotective effect on } \\
\text { dopaminergic neurons }\end{array}$ & Esteves et al., 2015 \\
\hline Chrysin & SLNs & $A D$ & $\begin{array}{l}\uparrow \text { Oral bioavailability, } \uparrow \text { free radical } \\
\text { scavenging, } \downarrow \text { neuronal damage }\end{array}$ & $\begin{array}{l}\text { Vedagiri and Thangarajan, } \\
2016\end{array}$ \\
\hline Sialic acid and peptide-B6 & Selenium nanoparticles & $A D$ & $\begin{array}{l}\text { Disaggregated the } A \beta \text { fibrils and } \\
\text { inhibited the } A \beta \text { aggregation }\end{array}$ & Yin et al., 2015 \\
\hline Cysteine & Selenium nanoparticles & $A D$ & $\downarrow$ ROS, prevented $A \beta$ aggregation & Zhou et al., 2015 \\
\hline Nattokinase enzyme (NK) & PNPs & $A D$ & Downregulate amyloid aggregation & Lohan et al., 2017 \\
\hline
\end{tabular}

inhibited its aggregation (Yin et al., 2015). Cysteine-modified SeNPs (D/LSeNPs) diminished ROS level and prevented metalinduced $A \beta$ aggregation. Furthermore, D/SeNPs showed a higher inhibitory effect on fibrils formation than L/SeNPs in vitro (Zhou et al., 2015). In the same way, (PLGA)encapsulated nattokinase conjugated with Tet1 peptide exhibited antifibrinolytic activity and downregulated the amyloid aggregation (Lohan et al., 2017) (Table 2).

\section{GREEN-EXTRACT NANOPARTICLES}

\section{Ginkgo biloba}

Ginkgo biloba (Ginkgoaceae) is an ancient Chinese tree, extensively cultivated for traditional and medical purposes. G. biloba extract contains flavonol glycosides, bilobalide, terpene trilactones, and varied forms of ginkgolides, and ginkgolic acid (Müller et al., 2012; Yang et al., 2018). In Europe, the standardized form of $G$. biloba extract is broadly used to improve the therapeutic condition of patients with various forms of dementia (Maurer et al., 1997; Luo, 2001). It was reported that niosome formulation of G. biloba extract was able to extend the release duration of flavonoid glycosides with improved oral bioavailability and pharmacokinetic properties, making it an appropriate delivery system for G. biloba extract to the brain (Jin et al., 2013). Nanosized particles of G. biloba extract promoted the release of acetylcholine neurotransmitter from certain parts of the brain compared with control group animals. Nanosized particles of G. biloba extract showed improved bioavailability and a better absorption character (Shinji et al., 2011).

\section{Pomegranate Seed Oil}

Pomegranate (Punica granatum) is a sacred fruit containing punicic acid (PA), and significant amounts of polyphenolic compounds (Kıralan et al., 2009; Vroegrijk et al., 2011; Boroushaki et al., 2016). In 2013, a nanodroplet formulation of pomegranate seed oil improved the Creutzfeldt Jacob disease (CJD). The results of the study exhibited that accumulation of scrapie isoform of the prion protein (PrPSc) did not show significant changes but neuronal loss and lipid oxidation relatively decreased, an indicative of neuroprotective function of pomegranate seed oil (Mizrahi et al., 2014). In mouse model of MS, nanodroplet formulation of pomegranate seed oil reduced the disease burden more than free pomegranate seed oil (Binyamin et al., 2015).

\section{Thymoquinone (TQ)}

The major active component of Nigella Sativa (Ranunculaceae) seed is TQ. TQ a lipophilic compound with diverse pharmacological qualities in immunomodulation, neurodegeneration and cognitive deficits (Alam et al., 2012). Nonetheless, the brain delivery of TQ is a challenge (Xiao et al., 2016). In high-fat cholesterol diet rats, nanoemulsion of TQ rich fraction (TQRF) and TQ improved memory deficits and enhanced the total antioxidant status, whereas significantly decreased the $\mathrm{A} \beta$ expression (Ismail et al., 2017b). In a similar condition, TQRF nanoemulsion and TQ nanoemulsion modulated the activity of $\gamma$ - and $\beta$-secretase enzymes, which consequently increasd the $\mathrm{A} \beta$ degradation and its elimination from the brain (Ismail et al., 2017a). Co-encapsulation of $N$. sativa oil (NSO) and plasmid DNA demonstrated that NSO could be used as a suitable gene delivery carrier for NDs treatment, especially in AD subjects (Doolaanea et al., 2016). In a study, TQ encapsulated chitosan NPs were tested for the nose to brain targeting method. Nose to brain targeting is a way to reduce the systemic adverse effect of TQ. The outcomes of the study confirmed the effectiveness of TQ, comparing with previous methods (Alam et al., 2012). 


\section{CONCLUSION}

In parallel with global improvement of lifespan, the prevalence of NDs is rising up, thereby, requiring novel treatment strategies to improve both the symptomatic and the quality of life in patients suffering from such disease. As known, the CNS is tightly preserved with various barriers. Thus, a proper drug essentially has to pass the BBB to reach the CNS. Nevertheless, numerous drug delivery systems designed and developed, however, phytochemical-based nanocarriers have distinguished advantages such as being safe, ecofriendly, less toxic, inexpensive, easy to scale up, and providing particles with controlled size and morphology. In sum, plant mediated nano systems can improve the pharmacokinetic profile and bioavailability of phyto-therapeutic compounds to the CNS, increase the brain penetration of these drugs, and enhance the disaggregation or prevent the aggregates formation in the brain. Although, there are

\section{REFERENCES}

Aalinkeel, R., Kutscher, H. L., Singh, A., Cwiklinski, K., Khechen, N., Schwartz, S. A., et al. (2018). Neuroprotective effects of a biodegradable poly (lactic-coglycolic acid)-ginsenoside $\mathrm{Rg} 3$ nanoformulation: a potential nanotherapy for Alzheimer's disease? J. Drug Target. 26, 182-193. doi: 10.1080/1061186x.2017. 1354002

Abhinav, K., Stanton, B., Johnston, C., Hardstaff, J., Orrell, R., Howard, R., et al. (2007). Amyotrophic lateral sclerosis in South-East England: a populationbased study. Neuroepidemiology 29, 44-48.

Ahmadi, M., Agah, E., Nafissi, S., Jaafari, M. R., Harirchian, M. H., Sarraf, P., et al. (2018). Safety and efficacy of nanocurcumin as add-on therapy to riluzole in patients with amyotrophic lateral sclerosis: a pilot randomized clinical trial. Neurotherapeutics 15, 430-438. doi: 10.1007/s13311-018-0606-7

Alam, S., Khan, Z. I., Mustafa, G., Kumar, M., Islam, F., Bhatnagar, A., et al. (2012). Development and evaluation of thymoquinone-encapsulated chitosan nanoparticles for nose-to-brain targeting: a pharmacoscintigraphic study. Intern. J. Nanomed. 7, 5705-5718. doi: 10.2147/IJN.S35329

Ali, T., Kim, M. J., Rehman, S. U., Ahmad, A., and Kim, M. O. (2017). Anthocyanin-loaded PEG-gold nanoparticles enhanced the neuroprotection of anthocyanins in an A $\beta$ 1-42 mouse model of Alzheimer's disease. Mol. Neurobiol. 54, 6490-6506. doi: 10.1007/s12035-016-0136-4

Aluani, D., Tzankova, V., Yordanov, Y., Kondeva-Burdina, M., Yoncheva, K. J. B., and Equipment, B. (2017). In vitro protective effects of encapsulated quercetin in neuronal models of oxidative stress injury. Biotechnol. Biotechnol. Equip. 31, 1055-1063. doi: 10.1080/13102818.2017.1347523

Alzheimer's and Dementia (2019). 2019 Alzheimer's disease facts and figures. Alzheimer's Dement. 15, 321-387. doi: 10.1016/j.jalz.2019.01.010

Aras, A., Guven, M., Akman, T., Ozkan, A., Sen, H., Duz, U., et al. (2015). Neuroprotective effects of daidzein on focal cerebral ischemia injury in rats. Neural Regen. Res. 10, 146-152. doi: 10.4103/1673-5374.150724

Aryani, A., and Denecke, B. (2016). Exosomes as a nanodelivery system: a key to the future of neuromedicine? Mol. Neurobiol. 53, 818-834. doi: 10.1007/s12035014-9054-5

Barreca, D., Bellocco, E., D’onofrio, G., Nabavi, S. F., Daglia, M., Rastrelli, L., et al. (2016). Neuroprotective effects of quercetin: from chemistry to medicine. CNS Neurol. Disord. Drug Targets 15, 964-975. doi: 10.2174/ 1871527315666160813175406

Bateman, R. J., Xiong, C., Benzinger, T. L., Fagan, A. M., Goate, A., Fox, N. C., et al. (2012). Clinical and biomarker changes in dominantly inherited alzheimer's disease. N. Engl. J. Med. 367, 795-804.

Bates, G. P., Dorsey, R., Gusella, J. F., Hayden, M. R., Kay, C., Leavitt, B. R., et al. (2015). Huntington disease. Nat. Rev. Dis. Primers 1:15005. doi: 10.1038/nrdp. 2015.5 many studies reporting the restorative effect of NPs in preclinical models of neurological disorders, further research is requisite to address the safety issues related to these systems. In addition, clinical efficacy of NPs in the area of neurological medicine needs long term assessments. Design of nanoformulations with more specificity for different brain cells and for each type of NDs should also be noticed.

\section{AUTHOR CONTRIBUTIONS}

SZM, MF, and MA designed the structure of the manuscript and drafted the manuscript. SM, MF, SZM performed the literature search and contributed in writing the manuscript. SZM, SM, and $\mathrm{ZB}$, reviewed and revised the manuscript. All authors had full access to the final version of the manuscript and gave their approval before publishing.

Beaulieu, J.-M., and Gainetdinov, R. R. (2011). The physiology, signaling, and pharmacology of dopamine receptors. Pharmacol. Rev. 63, 182-217. doi: 10. 1124/pr.110.002642

Bengmark, S. J. J. O. P., and Nutrition, E. (2006). Curcumin, an atoxic antioxidant and natural NFKB, cyclooxygenase-2, lipooxygenase, and inducible nitric oxide synthase inhibitor: a shield against acute and chronic diseases. JPEN J. Parenter. Enteral. Nutr. 30, 45-51. doi: 10.1177/014860710603000145

Bhaskar, S., Tian, F., Stoeger, T., Kreyling, W., De La Fuente, J. M., Grazú, V., et al. (2010). Multifunctional Nanocarriers for diagnostics, drug delivery and targeted treatment across blood-brain barrier: perspectives on tracking and neuroimaging. Particle Fibre Toxicol. 7:3. doi: 10.1186/1743-8977-7-3

Binyamin, O., Larush, L., Frid, K., Keller, G., Friedman-Levi, Y., Ovadia, H., et al. (2015). Treatment of a multiple sclerosis animal model by a novel nanodrop formulation of a natural antioxidant. Int. J. Nanomed. 10:7165. doi: 10.2147/ IJN.S92704

Biradar, S. M., Joshi, H., and Tarak, K. C. (2013). Cerebroprotective effect of isolated harmine alkaloids extracts of seeds of Peganum harmala L. on sodium nitriteinduced hypoxia and ethanol-induced neurodegeneration in young mice. Pak. J. Biol. Sci. 16, 1687-1697. doi: 10.3923/pjbs.2013.1687.1697

Bollimpelli, V. S., Kumar, P., Kumari, S., and Kondapi, A. K. J. N. I. (2016). Neuroprotective effect of curcumin-loaded lactoferrin nano particles against rotenone induced neurotoxicity. Neurochem. Intern. 95, 37-45. doi: 10.1016/ j.neuint.2016.01.006

Bondi, M., Montana, G., Craparo, E., Picone, P., Capuano, G., Carlo, M., et al. (2009). Ferulic acid-loaded lipid nanostructures as drug delivery systems for Alzheimer's disease: preparation, characterization and cytotoxicity studies. Curr. Nanosci. 5, 26-32. doi: 10.2174/157341309787314656

Boroushaki, M. T., Mollazadeh, H., and Afshari, R. A. (2016). Pomegranate seed oil: a comprehensive review on its therapeutic effects. Intern. J. Pharm. Sci. Res. 7:430.

Braak, H., Del Tredici, K., Rüb, U., De Vos, R. A., Steur, E. N. J., and Braak, E. (2003). Staging of brain pathology related to sporadic Parkinson's disease. Neurobiol. Aging 24, 197-211. doi: 10.1016/s0197-4580(02)00065-9

Brahmkhatri, V. P., Sharma, N., Sunanda, P., D'souza, A., Raghothama, S., and Atreya, H. S. (2018). Curcumin nanoconjugate Inhibits aggregation of N-terminal region $(\mathrm{A} \beta-16)$ of an amyloid beta peptide. N. J. Chem. 42, 1988119892. doi: 10.1039/c8nj03541e

Caruso, G., Caffo, M., Alafaci, C., Raudino, G., Cafarella, D., Lucerna, S., et al. (2011). Could nanoparticle systems have a role in the treatment of cerebral gliomas? Nanomed. Nanotechnol. Biol. Med. 7, 744-752. doi: 10.1016/j.nano. 2011.02.008

Chakraborty, S., Stalin, S., Das, N., Choudhury, S. T., Ghosh, S., and Swarnakar, S. J. B. (2012). The use of nano-quercetin to arrest mitochondrial damage and MMP-9 upregulation during prevention of gastric inflammation induced by 
ethanol in rat. Biomaterial 33, 2991-3001. doi: 10.1016/j.biomaterials.2011.12. 037

Chaudhuri, K. R., and Schapira, A. H. (2009). Non-motor symptoms of Parkinson's disease: dopaminergic pathophysiology and treatment. Lancet Neurol. 8, 464474. doi: 10.1016/s1474-4422(09)70068-7

Chen, X., and Pan, W. (2014). The treatment strategies for neurodegenerative diseases by integrative medicine. Integr. Med. Intern. 1, 223-225. doi: 10.1159/ 000381546

Cheng, K. K., Yeung, C. F., Ho, S. W., Chow, S. F., Chow, A. H. L., and Baum, L. J. T. (2013). Highly stabilized Curcumin nanoparticles tested in an in vitro blood-brain barrier model and in alzheimer's disease Tg2576 mice. AAPS J. 15, 324-336. doi: 10.1208/s12248-012-9444-4

Chonpathompikunlert, P., Wattanathorn, J., and Muchimapura, S. (2010). Piperine, the main alkaloid of thai black pepper, protects against neurodegeneration and cognitive impairment in animal model of cognitive deficit like condition of Alzheimer's disease. Food Chem. Toxicol. 48, 798-802. doi: 10.1016/j.fct.2009.12.009

Cirmi, S., Ferlazzo, N., Lombardo, G. E., Ventura-Spagnolo, E., Gangemi, S., Calapai, G., et al. (2016). Neurodegenerative diseases: might citrus flavonoids play a protective role? Molecules 21:312.

Da Rocha Lindner, G., Bonfanti Santos, D., Colle, D., Gasnhar Moreira, E. L., Daniel Prediger, R., Farina, M., et al. (2015). Improved neuroprotective effects of resveratrol-loaded polysorbate 80-coated poly (lactide) nanoparticles in MPTPinduced Parkinsonism. Intern. J. Pharm. Sci. Res. 10, 1127-1138. doi: 10.2217/ nnm.14.165

Dahiya, S., Rani, R., Dhingra, D., Kumar, S., and Dilbaghi, N. J. F. (2018). Potentiation of nootropic activity of EGCG loaded nanosuspension by piperine in swiss male albino mice. Science 4, 296-302. doi:10.1016/j.fjps.2018. 10.005

Davatgaran-Taghipour, Y., Masoomzadeh, S., Farzaei, M. H., Bahramsoltani, R., Karimi-Soureh, Z., Rahimi, R., et al. (2017). Polyphenol nanoformulations for cancer therapy: experimental evidence and clinical perspective. Intern. J. Nanomed. 12:2689. doi: 10.2147/IJN.S131973

David, M. A., and Tayebi, M. (2014). Detection of protein aggregates in brain and cerebrospinal fluid derived from multiple sclerosis patients. Front. Neurol. 5:251. doi: 10.3389/fneur.2014.00251

De Paula, V. D. J. R., Guimarães, F. M., Diniz, B. S., and Forlenza, O. V. (2009). Neurobiological pathways to Alzheimer's disease: Amyloid-beta, TAU protein or both? Dement. Neuropsychol. 3, 188-194. doi: 10.1590/s1980$57642009 \mathrm{dn} 30300003$

Del Prado-Audelo, M. L., Caballero-Florán, I. H., Meza-Toledo, J. A., MendozaMuñoz, N., González-Torres, M., Florán, B., et al. (2019). Formulations of Curcumin Nanoparticles for Brain Diseases. Biomolecules 9:56. doi: 10.3390/ biom 9020056

Del Tredici, K., and Braak, H. (2012). Lewy pathology and neurodegeneration in premotor Parkinson's disease. Mov. Disord. 27, 597-607. doi: 10.1002/mds. 24921

Demaagd, G., and Philip, A. (2015). Parkinson's disease and its management: part 1: disease entity, risk factors, pathophysiology, clinical presentation, and diagnosis. Pharm. Therap. 40:504.

Deng, X. Y., Li, H. Y., Chen, J. J., Li, R. P., Qu, R., Fu, Q., et al. (2015). Thymol produces an antidepressant-like effect in a chronic unpredictable mild stress model of depression in mice. Behav. Brain Res. 291, 12-19. doi: 10.1016/j.bbr. 2015.04.052

Desai, A. K., and Grossberg, G. T. (2005). Diagnosis and treatment of Alzheimer's disease. Neurology 64, S34-S39.

Dhawan, S., Kapil, R., and Singh, B. (2011). Formulation development and systematic optimization of solid lipid nanoparticles of quercetin for improved brain delivery. J. Pharm. Pharmacol. 63, 342-351. doi: 10.1111/j.2042-7158. 2010.01225.x

Dolati, S., Aghebati-Maleki, L., Ahmadi, M., Marofi, F., Babaloo, Z., Ayramloo, H., et al. (2018a). Nanocurcumin restores aberrant miRNA expression profile in multiple sclerosis, randomized, double-blind, placebo-controlled trial. JPP 233, 5222-5230. doi: 10.1002/jcp.26301

Dolati, S., Ahmadi, M., Aghebti-Maleki, L., Nikmaram, A., Marofi, F., Rikhtegar, R., et al. (2018b). Nanocurcumin is a potential novel therapy for multiple sclerosis by influencing inflammatory mediators. Pharmacol. Rep. 70, 1158-1167. doi: 10.1016/j.pharep.2018.05.008
Dolati, S., Babaloo, Z., Ayromlou, H., Ahmadi, M., Rikhtegar, R., Rostamzadeh, D., et al. (2019). Nanocurcumin improves regulatory T-cell frequency and function in patients with multiple sclerosis. J. Neuroimmunol. 327, 15-21. doi: 10.1016/j. jneuroim.2019.01.007

Doody, R., Ferris, S., Salloway, S., Sun, Y., Goldman, R., Watkins, W., et al. (2009). Donepezil treatment of patients with MCI: a 48-week randomized, placebocontrolled trial. Neurology 72, 1555-1561. doi: 10.1212/01.wnl.0000344650. 95823.03

Doolaanea, A. A., Mansor, N. I., Mohd Nor, N. H., and Mohamed, F. J. J. O. M. (2016). Co-encapsulation of Nigella sativa oil and plasmid DNA for enhanced gene therapy of Alzheimer's disease. J. Microencapsul. 33, 114-126. doi: 10.3109/ 02652048.2015.1134689

Duda, J. E., Giasson, B. I., Gur, T. L., Montine, T. J., Robertson, D., Biaggioni, I., et al. (2000). Immunohistochemical and biochemical studies demonstrate a distinct profile of $\alpha$-synuclein permutations in multiple system atrophy. J. Neuropathol. Exp. Neurol. 59, 830-841. doi:10.1093/jnen/59. 9.830

Durães, F., Pinto, M., and Sousa, E. (2018). Old Drugs as New Treatments for Neurodegenerative Diseases. Pharmaceuticals 11:44. doi: 10.3390/ph11020044

Dwivedi, N., Shah, J., Mishra, V., Tambuwala, M., and Kesharwani, P. (2019). Nanoneuromedicine for management of neurodegenerative disorder. J. Drug Deliv. Sci. Technol. 49, 477-490. doi:10.1016/j.jddst.2018. 12.021

Elnaggar, Y. S., Etman, S. M., Abdelmonsif, D. A., and Abdallah, O. Y. (2015b). Novel piperine-loaded Tween-integrated monoolein cubosomes as braintargeted oral nanomedicine in Alzheimer's disease: pharmaceutical, biological, and toxicological studies. Int. J. Nanomed. 10:5459. doi: 10.2147/ijn.s87336

Elnaggar, Y. S., Etman, S. M., Abdelmonsif, D. A., and Abdallah, O. Y. (2015a). Intranasal piperine-loaded chitosan nanoparticles as brain-targeted therapy in Alzheimer's disease: optimization, biological efficacy, and potential toxicity. J. Pharm. Sci. 104, 3544-3556. doi: 10.1002/jps.24557

Esteves, M., Cristóvão, A. C., Saraiva, T., Rocha, S. M., Baltazar, G., Ferreira, L., et al. (2015). Retinoic acid-loaded polymeric nanoparticles induce neuroprotection in a mouse model for Parkinson's disease. Front. Aging Neurosci. 7:20. doi: 10.3389/fnagi.2015.00020

Etman, S. M., Elnaggar, Y. S., Abdelmonsif, D. A., and Abdallah, O. Y. (2018). Oral brain-targeted microemulsion for enhanced piperine delivery in Alzheimer's Disease therapy: in vitro appraisal. In Vivo activity, and nanotoxicity. AAPS Pharm. Sci. Tech. 19, 3698-3711. doi: 10.1208/s12249-0181180-3

Farzaei, M. H., Rahimi, R., Nikfar, S., and Abdollahi, M. (2018a). Effect of resveratrol on cognitive and memory performance and mood: A metaanalysis of 225 patients. Pharmacol. Res. 128, 338-344. doi: 10.1016/j.phrs.2017. 08.009

Farzaei, M. H., Shahpiri, Z., Mehri, M. R., Bahramsoltani, R., Rezaei, M., Raeesdana, A., et al. (2018b). Medicinal plants in neurodegenerative diseases: perspective of traditional Persian medicine. Curr. Drug Metab. 19, 429-442. doi: 10.2174/1389200219666180305150256

Friese, M. A., Schattling, B., and Fugger, L. (2014). Mechanisms of neurodegeneration and axonal dysfunction in multiple sclerosis. Nat. Rev. Neurol. 10:225. doi: 10.1038/nrneurol.2014.37

Frozza, R. L., Bernardi, A., Hoppe, J. B., Meneghetti, A. B., Battastini, A. M., Pohlmann, A. R., et al. (2013a). Lipid-core nanocapsules improve the effects of resveratrol against Abeta-induced neuroinflammation. J. Biomed. Nanotechnol. 9, 2086-2104. doi: 10.1166/jbn.2013.1709

Frozza, R. L., Bernardi, A., Hoppe, J. B., Meneghetti, A. B., Matte, A., Battastini, A. M., et al. (2013b). Neuroprotective effects of resveratrol against Abeta administration in rats are improved by lipid-core nanocapsules. Mol. Neurobiol. 47, 1066-1080. doi: 10.1007/s12035-013-8401-2

Fünfschilling, U., Supplie, L. M., Mahad, D., Boretius, S., Saab, A. S., Edgar, J., et al. (2012). Glycolytic oligodendrocytes maintain myelin and long-term axonal integrity. Nature 485:517. doi: 10.1038/nature11007

Ganesan, P., Ko, H.-M., Kim, I.-S., and Choi, D.-K. (2015). Recent trends in the development of nanophytobioactive compounds and delivery systems for their possible role in reducing oxidative stress in Parkinson's disease models. Intern. J. Nanomed. 10:6757. doi: 10.2147/ijn.s93918

Ghaffari, F., Moghaddam, A. H., Zare, M. J. B., and Neuroscience, C. (2018). Neuroprotective effect of quercetin nanocrystal in a 6-hydroxydopamine model 
of parkinson disease: biochemical and behavioral evidence. Basic Clin. Neurosci. 9:317. doi: 10.32598/bcn.9.5.317

Ghosh, A., Sarkar, S., Mandal, A. K., and Das, N. J. P. O. (2013). Neuroprotective role of nanoencapsulated quercetin in combating ischemia-reperfusion induced neuronal damage in young and aged rats. PLoS One 8:e57735. doi: 10.1371/ journal.pone.0057735

Ghosh, S., Sarkar, S., Choudhury, S. T., Ghosh, T., and Das, N. J. (2017). Triphenyl phosphonium coated nano-quercetin for oral delivery: neuroprotective effects in attenuating age related global moderate cerebral ischemia reperfusion injury in rats. Nanomedicine 13, 2439-2450. doi: 10.1016/j.nano.2017. 08.002

Goetz, C. G. (2000). Amyotrophic lateral sclerosis: early contributions of Jean-Martin Charcot. Muscle Nerve 23, 336-343. doi: 10.1002/(sici)10974598(200003)23:3<336::aid-mus4>3.0.co;2-1

Gomes, B. A. Q., Silva, J., Bastos, O. P., Romeiro, C. F. R., Dos Santos, S., Monteiro, V., et al. (2018). Neuroprotective mechanisms of resveratrol in alzheimer's disease: role of SIRT1. Oxid. Med. Cell. Longev. 2018:15.

Guo, Y. Z., He, P., and Feng, A. M. (2017). Effect of curcumin on expressions of NF-кBp65, TNF- $\alpha$ and IL- 8 in placental tissue of premature birth of infected mice. Asian Pac. J. Trop. Med. 10, 175-178. doi: 10.1016/j.apjtm.2017.01.004

Hajialyani, M., Tewari, D., Sobarzo-Sánchez, E., Nabavi, S. M., Farzaei, M. H., and Abdollahi, M. (2018). Natural product-based nanomedicines for wound healing purposes: therapeutic targets and drug delivery systems. Intern. J. Nanomed. 13:5023. doi: 10.2147/IJN.S174072

Hassanzadeh, P., Arbabi, E., Atyabi, F., and Dinarvand, R. J. L. S. (2018). Ferulic acid-loaded nanostructured lipid carriers: a promising nanoformulation against the ischemic neural injuries. Life Sci. 193, 64-76. doi: 10.1016/j.lfs.2017.11.046

He, X., Yang, S., Zhang, R., Hou, L., Xu, J., Hu, Y., et al. (2019). Smilagenin protects dopaminergic neurons in chronic MPTP/Probenecid-lesioned Parkinson's disease models. Front. Cell. Neurosci. 13:18. doi: 10.3389/fncel.2019.00018

Heron, M. P. (2018). Deaths: leading causes for 2016. Natl. Vital. Stat. Rep. 67, $1-77$.

Hodjat, M., Rahmani, S., Khan, F., Niaz, K., Navaei-Nigjeh, M., Nejad, S. M., et al. (2017). Environmental toxicants, incidence of degenerative diseases, and therapies from the epigenetic point of view. Archiv. Toxicol. 91, 2577-2597. doi: 10.1007/s00204-017-1979-9

Hoppe, J. B., Coradini, K., Frozza, R. L., Oliveira, C. M., Meneghetti, A. B., Bernardi, A., et al. (2013). Free and nanoencapsulated curcumin suppress $\beta$-amyloid-induced cognitive impairments in rats: involvement of BDNF and Akt/GSK-3 $\beta$ signaling pathway. Neurobiol. Learn. Mem. 106, 134-144. doi: 10.1016/j.nlm.2013.08.001

Hu, S., Maiti, P., Ma, Q., Zuo, X., Jones, M. R., Cole, G. M., et al. (2015). Clinical development of curcumin in neurodegenerative disease. Expert. Rev. Neurother. 15, 629-637. doi: 10.1586/14737175.2015.1044981

Huo, X., Zhang, Y., Jin, X., Li, Y., and Zhang, L. (2019). A novel synthesis of selenium nanoparticles encapsulated PLGA nanospheres with curcumin molecules for the inhibition of amyloid $\beta$ aggregation in Alzheimer's disease. J. Photochem. Photobiol. B Biol. 190, 98-102. doi: 10.1016/j.jphotobiol.2018.11. 008

Hussain, G., Rasul, A., Anwar, H., Aziz, N., Razzaq, A., Wei, W., et al. (2018). Role of plant derived alkaloids and their mechanism in neurodegenerative disorders. Intern. J. Biol. Sci. 14, 341-357. doi: 10.7150/ijbs.23247

Ismail, N., Ismail, M., Azmi, N. H., Bakar, M. F. A., Yida, Z., Abdullah, M. A., et al. (2017a). Thymoquinone-rich fraction nanoemulsion (TQRFNE) decreases $\mathrm{A} \beta 40$ and $\mathrm{A} \beta 42$ levels by modulating APP processing, up-regulating IDE and LRP1, and down-regulating BACE1 and RAGE in response to high fat/cholesterol diet-induced rats. Biomed. Pharmacothe. 95, 780-788. doi: 10 . 1016/j.biopha.2017.08.074

Ismail, N., Ismail, M., Azmi, N. H., Bakar, M. F. A., Yida, Z., Stanslas, J., et al. (2017b). Beneficial effects of TQRF and TQ nano-and conventional emulsions on memory deficit, lipid peroxidation, total antioxidant status, antioxidants genes expression and soluble $\mathrm{A} \beta$ levels in high fat-cholesterol diet-induced rats. Chem. Biol. Interact 275, 61-73. doi: 10.1016/j.cbi.2017.07.014

Jain, S., Ancheria, R. K., Shrivastava, S., Soni, S. L., and Sharma, M. (2019). An overview of nanogel-novel drug delivery system. Asian J. Pharm. Res. Dev. 7, 47-55. doi: 10.22270/ajprd.v7i2.482

Jan, A. T., Malik, M. A., Rahman, S., Yeo, H. R., Lee, E. J., Abdullah, T. S., et al. (2017). Perspective insights of exosomes in neurodegenerative diseases: a critical appraisal. Front. Aging Neurosci. 9:317. doi: 10.3389/fnagi.2017. 00317

Jayamani, J., and Shanmugam, G. (2014). Gallic acid, one of the components in many plant tissues, is a potential inhibitor for insulin amyloid fibril formation. Eur. J. Med. Chem. 85, 352-358. doi: 10.1016/j.ejmech.2014.07.111

Jiang, B., Shen, R. F., Bi, J., Tian, X. S., Hinchliffe, T., and Xia, Y. (2015). Catalpol: a potential therapeutic for neurodegenerative diseases. Curr. Med. Chem. 22, 1278-1291. doi: 10.2174/0929867322666150114151720

Jiang, W., Li, S., and Li, X. (2015). Therapeutic potential of berberine against neurodegenerative diseases. Sci. China Life Sci. 58, 564-569. doi: 10.1007/ s11427-015-4829-0

Jin, Y., Wen, J., Garg, S., Liu, D., Zhou, Y., Teng, L., et al. (2013). Development of a novel niosomal system for oral delivery of Ginkgo biloba extract. Int. J. Nanomed. 8:421. doi: 10.2147/IJN.S37984

Jose, S., Sowmya, S., Cinu, T., Aleykutty, N., Thomas, S., and Souto, E. (2014). Surface modified PLGA nanoparticles for brain targeting of Bacoside-A. Eur. J. Pharm. Sci. 63, 29-35. doi: 10.1016/j.ejps.2014.06.024

Kakkar, V., and Kaur, I. P. (2011). Evaluating potential of curcumin loaded solid lipid nanoparticles in aluminium induced behavioural, biochemical and histopathological alterations in mice brain. Food Chem. Toxicol. 49, 2906-2913. doi: 10.1016/j.fct.2011.08.006

Kay, C., Fisher, E., and Hayden, M. (2014). “Huntington's Disease chapter 7," in Handbook of Clinical Neurology, eds G. P. Bates, S. J. Tabrizi, and L. Jones (Oxford: Oxford University Press).

Khazdair, M. R. (2015). The protective effects of nigella sativa and its constituents on induced neurotoxicity. J. Toxicol. 2015:841823. doi: 10.1155/2015/ 841823

Kheradmand, E., Hajizadeh Moghaddam, A., and Zare, M. (2018). Neuroprotective effect of hesperetin and nano-hesperetin on recognition memory impairment and the elevated oxygen stress in rat model of Alzheimer's disease. Biomed. Pharmacother. 97, 1096-1101. doi: 10.1016/j.biopha.2017.11.047

Kim, J., Lee, H. J., and Lee, K. W. (2010). Naturally occurring phytochemicals for the prevention of Alzheimer's disease. J. Neurochem. 112, 1415-1430. doi: 10.1111/j.1471-4159.2009.06562.x

Kim, M. H., Kim, S.-H., and Yang, W. M. (2014). Mechanisms of action of phytochemicals from medicinal herbs in the treatment of Alzheimer's disease. Plant. Med. 80, 1249-1258. doi: 10.1055/s-0034-1383038

Kim, M. J., Rehman, S. U., Amin, F. U., and Kim, M. O. (2017). Enhanced neuroprotection of anthocyanin-loaded PEG-gold nanoparticles against $A \beta 1-42$-induced neuroinflammation and neurodegeneration via the NFKB/JNK/GSK3 $\beta$ signaling pathway. Nanomedicine 13, 2533-2544. doi: 10.1016/ j.nano.2017.06.022

Kori, M., Ayd $\imath$ n, B., Unal, S., Arga, K. Y., and Kazan, D. (2016). Metabolic biomarkers and neurodegeneration: a pathway enrichment analysis of Alzheimer's disease, Parkinson's disease, and amyotrophic lateral sclerosis. Omics 20, 645-661. doi: 10.1089/omi.2016.0106

Kumar, P., Sharma, G., Kumar, R., Singh, B., Malik, R., Katare, O. P., et al. (2016). Promises of a biocompatible nanocarrier in improved brain delivery of quercetin: biochemical, pharmacokinetic and biodistribution evidences. Int. J. Pharm. 515, 307-314. doi: 10.1016/j.ijpharm.2016.10.024

Kundu, P., Das, M., Tripathy, K., and Sahoo, S. K. (2016). Delivery of dual drug loaded lipid based nanoparticles across the blood-brain barrier impart enhanced neuroprotection in a rotenone induced mouse model of Parkinson's disease. ACS Chem. Neurosci. 7, 1658-1670. doi: 10.1021/acschemneuro. 6b00207

Kuo, Y. C., Chen, I. Y., and Rajesh, R. J. (2018). Use of functionalized liposomes loaded with antioxidants to permeate the blood-brain barrier and inhibit $\beta$-amyloid-induced neurodegeneration in the brain. J. Taiwan Instit. Chem. Eng. 87, 1-14. doi: 10.1016/j.jtice.2018.03.001

Kutzelnigg, A., and Lassmann, H. (2014). Pathology of multiple sclerosis and related inflammatory demyelinating diseases. Handb. Clin. Neurol. 122, 15-58. doi: 10.1016/B978-0-444-52001-2.00002-9

Kıralan, M., Gölükcü, M., and Tokgöz, H. J. (2009). Oil and conjugated linolenic acid contents of seeds from important pomegranate cultivars (Punica granatum L.) grown in Turkey. J. Am. Oil Chem. Soc. 86, 985-990. doi: 10.1007/s11746009-1436-x

Lagoa, R., Lopez-Sanchez, C., Samhan-Arias, A., Ganan, C., Garcia-Martinez, V., and Gutiérrez-Merino, C. (2009). "Neuroprotective effect of kaempferol in the 
3-nitropropionic acid model of Huntington's disease," in Proceedings of the Europe Meeting 2009 of the Society-for-Free-Radicals-Research, Berlin.

Lee, Y., Morrison, B. M., Li, Y., Lengacher, S., Farah, M. H., Hoffman, P. N., et al. (2012). Oligodendroglia metabolically support axons and contribute to neurodegeneration. Nature 487:443. doi: 10.1038/nature11314

Li, F., Harmer, P., Fitzgerald, K., Eckstrom, E., Stock, R., Galver, J., et al. (2012). Tai chi and postural stability in patients with Parkinson's disease. N. Engl. J. Med. 366, 511-519. doi: 10.1056/NEJMoa1107911

Li, J., Zhou, L., Ye, D., Huang, S., Shao, K., Huang, R., et al. (2011). Cholinederivate-modified nanoparticles for brain-targeting gene delivery. Adv. Mater. 23, 4516-4520. doi: 10.1002/adma.201101899

Lloret, S. P., Rey, M. V., and Rascol, O. (2013). Ayurveda medicine for the treatment of Parkinson's Disease. Int. Integrat. Med. 1, 1-6.

Logroscino, G., Traynor, B., Hardiman, O., Couratier, P., Mitchell, J., Swingler, R., et al. (2008). Descriptive epidemiology of amyotrophic lateral sclerosis: new evidence and unsolved issues. J. Neurol. Neurosurg. Psychiatr. 79, 6-11. doi: 10.1136/jnnp.2006.104828

Logroscino, G., Traynor, B. J., Hardiman, O., Chiò, A., Mitchell, D., Swingler, R. J., et al. (2010). Incidence of amyotrophic lateral sclerosis in Europe. J. Neurol. Neurosurg. Psychiatr. 81, 385-390.

Lohan, S., Raza, K., Mehta, S. K., Bhatti, G. K., Saini, S., and Singh, B. (2017). Anti-Alzheimer's potential of berberine using surface decorated multi-walled carbon nanotubes: a preclinical evidence. Intern. J. Pharm. 530, 263-278. doi: 10.1016/j.ijpharm.2017.07.080

Lu, X., Ji, C., Xu, H., Li, X., Ding, H., Ye, M., et al. (2009). Resveratrol-loaded polymeric micelles protect cells from $\mathrm{A} \beta$-induced oxidative stress. Brain Res. 375, 89-96. doi: 10.1016/j.ijpharm.2009.03.021

Luo, Y. (2001). Ginkgo biloba neuroprotection: therapeutic implications in Alzheimer's disease. J. Alzheimers Dis. 3, 401-407. doi: 10.3233/jad-2001-3407

Maravajhala, V., Papishetty, S., and Bandlapalli, S. (2012). Nanotechnology in development of drug delivery system. Intern. J. Pharm. Sci. Res. 3:84.

Marin, L. D., Sanchez-Borzone, M., and Garcia, D. A. (2011). Comparative antioxidant properties of some GABAergic phenols and related compounds, determined for homogeneous and membrane systems. Med. Chem. 7, 317-324. doi: $10.2174 / 157340611796150969$

Mathew, A., Fukuda, T., Nagaoka, Y., Hasumura, T., Morimoto, H., Yoshida, Y., et al. (2012). Curcumin loaded-PLGA nanoparticles conjugated with Tet1 peptide for potential use in Alzheimer's disease. PLoS One 7:e32616. doi: 10.1371/journal.pone.0032616

Maurer, K., Ihl, R., Dierks, T., and Frölich, L. J. (1997). Clinical efficacy of Ginkgo biloba special extract EGb 761 in dementia of the Alzheimer type. J. Psychiatr. Res. 31, 645-655. doi: 10.1016/s0022-3956(97)00022-8

Mckeith, I. G., Galasko, D., Kosaka, K., Perry, E., Dickson, D. W., Hansen, L., et al. (1996). Consensus guidelines for the clinical and pathologic diagnosis of dementia with Lewy bodies (DLB): report of the consortium on DLB international workshop. Neurology 47, 1113-1124.

Meng, F., Asghar, S., Gao, S., Su, Z., Song, J., Huo, M., et al. (2015). A novel LDLmimic nanocarrier for the targeted delivery of curcumin into the brain to treat Alzheimer's disease. Coll. Surf. B Biointerf. 134, 88-97. doi: 10.1016/j.colsurfb. 2015.06.025

Meng, Q., Wang, A., Hua, H., Jiang, Y., Wang, Y., Mu, H., et al. (2018). Intranasal delivery of Huperzine A to the brain using lactoferrin-conjugated $\mathrm{N}$-trimethylated chitosan surface-modified PLGA nanoparticles for treatment of Alzheimer's disease. Intern. Nanomed. 13:705. doi: 10.2147/ijn.s151474

Mhillaj, E., Catino, S., Miceli, F. M., Santangelo, R., Trabace, L., Cuomo, V., et al. (2018). Ferulic acid improves cognitive skills through the activation of the heme oxygenase system in the rat. Mol. Neurobiol. 55, 905-916. doi: 10.1007/s12035017-0381-1

Min, J. B., Kim, E. S., Lee, J.-S., and Lee, H. G. J. F. S. (2018). Preparation, characterization, and cellular uptake of resveratrol-loaded trimethyl chitosan nanoparticles. Food Sci. Biotechnol. 27, 1-10. doi: 10.1007/s10068-017-0272-2

Mizrahi, M., Friedman-Levi, Y., Larush, L., Frid, K., Binyamin, O., Dori, D., et al. (2014). Pomegranate seed oil nanoemulsions for the prevention and treatment of neurodegenerative diseases: the case of genetic CJD. Nanomedicine 10, 1353-1363. doi: 10.1016/j.nano.2014.03.015

Mizuno, Y. (2014). Recent research progress in and future perspective on treatment of Parkinson's disease. Integr. Med. Intern. 1, 67-79. doi: 10.1159/0003 65571
Modi, G., Pillay, V., and Choonara, Y. E. (2010). Advances in the treatment of neurodegenerative disorders employing nanotechnology. Ann. N. Y. Acad. Sci. 1184, 154-172. doi: 10.1111/j.1749-6632.2009.05108.x

Modi, G., Pillay, V., Choonara, Y. E., Ndesendo, V. M., Du Toit, L. C., and Naidoo, D. (2009). Nanotechnological applications for the treatment of neurodegenerative disorders. Prog. Neurobiol. 88, 272-285. doi: 10.1016/j. pneurobio.2009.05.002

Mohajeri, M., Sadeghizadeh, M., Najafi, F., and Javan, M. J. N. (2015). Polymerized nano-curcumin attenuates neurological symptoms in EAE model of multiple sclerosis through down regulation of inflammatory and oxidative processes and enhancing neuroprotection and myelin repair. Neuropharmacology 99, 156-167. doi: 10.1016/j.neuropharm.2015.07.013

Mohammad-Beigi, H., Morshedi, D., Shojaosadati, S. A., Pedersen, J. N., Marvian, A. T., Aliakbari, F., et al. (2016). Gallic acid loaded onto polyethyleniminecoated human serum albumin nanoparticles (PEI-HSA-GA NPs) stabilizes $\alpha$-synuclein in the unfolded conformation and inhibits aggregation. RSC Adv. 6, 85312-85323. doi: 10.1039/c6ra08502d

Momtaz, S., Hassani, S., Khan, F., Ziaee, M., and Abdollahi, M. (2018). Cinnamon, a promising prospect towards Alzheimer's disease. Pharmacol. Res. 130, 241-258. doi: 10.1016/j.phrs.2017.12.011

Morgan, S., and Orrell, R. W. (2016). Pathogenesis of amyotrophic lateral sclerosis. Br. Med. Bull. 119, 87-98. doi: 10.1093/bmb/ldw026

Morozova, N., Weisskopf, M. G., Mccullough, M. L., Munger, K. L., Calle, E. E., Thun, M. J., et al. (2008). Diet and amyotrophic lateral sclerosis. Epidemiology 19, 324-337. doi: 10.1097/EDE.0b013e3181632c5d

Mourtas, S., Canovi, M., Zona, C., Aurilia, D., Niarakis, A., La Ferla, B., et al. (2011). Curcumin-decorated nanoliposomes with very high affinity for amyloidB1-42 peptide. Biomaterials 32, 1635-1645. doi: 10.1016/j.biomaterials.2010. 10.027

Mourtas, S., Lazar, A. N., Markoutsa, E., Duyckaerts, C., and Antimisiaris, S. G. (2014). Multifunctional nanoliposomes with curcumin-lipid derivative and brain targeting functionality with potential applications for Alzheimer disease. Eur. J. Med. Chem. 80, 175-183. doi: 10.1016/j.ejmech.2014.04.050

Mulik, R. S., Mönkkönen, J., Juvonen, R. O., Mahadik, K. R., and Paradkar, A. R. (2010). ApoE3 mediated Poly(butyl) cyanoacrylate nanoparticles containing curcumin: study of enhanced activity of curcumin against beta amyloid induced cytotoxicity using in vitro cell culture model. Mol. Pharm. 7, 815-825. doi: 10.1021/mp900306x

Müller, W. E., Heiser, J., and Leuner, K. J. I. P. (2012). Effects of the standardized Ginkgo biloba extract EGb 761 on neuroplasticity. Int. Psychogeriatr. 24, S21S24. doi: 10.1017/S1041610212000592

Nabavi, S. F., Devi, K. P., Malar, D. S., Sureda, A., Daglia, M., and Nabavi, S. M. (2015). Ferulic acid and Alzheimer's disease: promises and pitfalls. Mini. Rev. Med. Chem. 15, 776-788. doi: 10.2174/138955751566615052210 2545

Naeimi, R., Safarpour, F., Hashemian, M., Tashakorian, H., Ahmadian, S. R., Ashrafpour, M., et al. (2018). Curcumin-loaded nanoparticles ameliorate glial activation and improve myelin repair in lyolecithin-induced focal demyelination model of rat corpus callosum. Neurosci. Lett. 674, 1-10. doi: 10.1016/j.neulet.2018.03.018

Nagpal, K., Singh, S., and Mishra, D. J. D. D. (2013). Nanoparticle mediated brain targeted delivery of gallic acid: in vivo behavioral and biochemical studies for protection against scopolamine-induced amnesia. Drug Deliv. 20, 112-119. doi: 10.3109/10717544.2013.779330

Naoi, M., Inaba-Hasegawa, K., Shamoto-Nagai, M., and Maruyama, W. (2017). Neurotrophic function of phytochemicals for neuroprotection in aging and neurodegenerative disorders: modulation of intracellular signaling and gene expression. J. Neural Trans. 124, 1515-1527. doi: 10.1007/s00702-017-1797-5

Naoi, M., Shamoto-Nagai, M., and Maruyama, W. (2019). Neuroprotection of multifunctional phytochemicals as novel therapeutic strategy for neurodegenerative disorders: antiapoptotic and antiamyloidogenic activities by modulation of cellular signal pathways. Future Med. 14:FNL9.

Nathiya, S., Durga, M., and Devasena, T. J. A. (2014). Quercetin, encapsulated quercetin and its application-A review. Intern. J. Pharm. Pharm. Sci. 6, 20-26.

Naz, S., Shamoon, M., Wang, R., Zhang, L., Zhou, J., and Chen, J. (2019). Advances in therapeutic implications of inorganic drug delivery nano-platforms for cancer. Intern. J. Mol. Sci 20:965. doi: 10.3390/ijms20040965 
Neves, A. R., Queiroz, J. F., and Reis, S. J. J. O. N. (2016). Brain-targeted delivery of resveratrol using solid lipid nanoparticles functionalized with apolipoprotein $\mathrm{E}$. J. Nanobiotechnol. 14:27. doi: 10.1186/s12951-016-0177-x

Nisi Zhang, F. Y., Liang, X., Wu, M., Shen, Y., Chen, M., Xu, Y., et al. (2018). Localized delivery of curcumin into brain with polysorbate 80-modified cerasomes by ultrasound-targeted microbubble destruction for improved Parkinson's disease therapy. Theranostics 8, 2264-2277. doi: 10.7150/thno. 23734

Niu, X., Chen, J., and Gao, J. (2019). Nanocarriers as a powerful vehicle to overcome blood-brain barrier in treating neurodegenerative diseases: focus on recent advances. Asian J. Pharm. Sci. 14, 480-496. doi: 10.1016/j.ajps.2018.09.005

Ochekpe, N. A., Olorunfemi, P. O., and Ngwuluka, N. C. (2009). Nanotechnology and drug delivery part 1: background and applications. Trop. J. Pharm. Res. 8, 265-274. doi: 10.2174/1871520619666191028112258

Okun, M. S. (2014). Deep-brain stimulation-entering the era of human neuralnetwork modulation. N. Engl. J. Med. 371, 1369-1373. doi: 10.1056/ nejmp1408779

Pagliosa, L. B., Monteiro, S. C., Silva, K. B., De Andrade, J. P., Dutilh, J., Bastida, J., et al. (2010). Effect of isoquinoline alkaloids from two Hippeastrum species on in vitro acetylcholinesterase activity. Phytomedicine 17, 698-701. doi: 10.1016/j. phymed.2009.10.003

Pan, W., Kwak, S., Liu, Y., Sun, Y., Fang, Z., Qin, B., et al. (2011a). Traditional chinese medicine improves activities of daily living in Parkinson's disease. Parkinson Dis. 2011:789506.

Pan, W., Liu, Y., Fang, Z., Zhu, X., Pan, W., Kwak, S., et al. (2011b). A compound belonging to traditional Chinese medicine improves nocturnal activity in Parkinson's disease. Sleep Med. 12:307. doi: 10.1016/j.sleep.2010.07.016

Pan, W., Wang, Q., Kwak, S., Song, Y., Qin, B., Wang, M., et al. (2014). Shen-zhiling oral liquid improves behavioral and psychological symptoms of dementia in Alzheimer's disease. Evid. Based Complem. Altern. Med. 2014:6.

Pan, W., and Zhou, H. (2014). Inclusion of integrative medicine in clinical practice. Integr. Med. Intern. 1, 1-4. doi: 10.1159/000362628

Pandareesh, M. D., Mythri, R. B., and Srinivas Bharath, M. M. (2015). Bioavailability of dietary polyphenols: factors contributing to their clinical application in CNS diseases. Neurochem. Intern. 89, 198-208. doi: 10.1016/j. neuint.2015.07.003

Pangeni, R., Sharma, S., Mustafa, G., Ali, J., and Baboota, S. J. N. (2014). Vitamin E loaded resveratrol nanoemulsion for brain targeting for the treatment of Parkinson's disease by reducing oxidative stress. Nanotechnology 25:485102. doi: 10.1088/0957-4484/25/48/485102

Patil, S. P., Jain, P. D., Sancheti, J. S., Ghumatkar, P. J., Tambe, R., and Sathaye, S. (2014). Neuroprotective and neurotrophic effects of Apigenin and Luteolin in MPTP induced parkinsonism in mice. Neuropharmacology 86, 192-202. doi: 10.1016/j.neuropharm.2014.07.012

Penke, B., Bogár, F., and Fülöp, L. (2017). $\beta$-Amyloid and the Pathomechanisms of Alzheimer's disease: a comprehensive view. Molecules 22:1692. doi: 10.3390/ molecules 22101692

Phachonpai, W., Wattanathorn, J., Muchimapura, S., Tong-Un, T., and Preechagoon, D. J. (2010). Neuroprotective effect of quercetin encapsulated liposomes: a novel therapeutic strategy against Alzheimer's disease. Am. J. Appl. Sci. 7, 480-485. doi: 10.3844/ajassp.2010.480.485

Picone, P., Bondi, M. L., Picone, P., Bondi, M. L., Montana, G., Bruno, A., et al. (2009). Ferulic acid inhibits oxidative stress and cell death induced by $\mathrm{Ab}$ oligomers: improved delivery by solid lipid nanoparticles. Free Radic. Res. 43, 1133-1145. doi: 10.1080/10715760903214454

Polman, C. H., Reingold, S. C., Banwell, B., Clanet, M., Cohen, J. A., Filippi, M., et al. (2011). Diagnostic criteria for multiple sclerosis: 2010 revisions to the McDonald criteria. Ann. Neurol. 69, 292-302. doi: 10.1002/ana.22366

Poovaiah, N., Davoudi, Z., Peng, H., Schlichtmann, B., Mallapragada, S., Narasimhan, B., et al. (2018). Treatment of neurodegenerative disorders through the blood-brain barrier using nanocarriers. Nanoscale 10, $16962-$ 16983. doi: 10.1039/c8nr04073g

Prema, A., Janakiraman, U., Manivasagam, T., and Thenmozhi, A. J. (2015). Neuroprotective effect of lycopene against MPTP induced experimental Parkinson's disease in mice. Neurosci. Lett. 599, 12-19. doi: 10.1016/j.neulet. 2015.05.024

Price, J. L., Davis, P., Morris, J., and White, D. (1991). The distribution of tangles, plaques and related immunohistochemical markers in healthy aging and Alzheimer's disease. Neurobiol. Aging 12, 295-312. doi: 10.1016/01974580(91)90006-6

Przedborski, S., Vila, M., and Jackson-Lewis, V. (2003). Neurodegeneration: what is it and where are we? J. Clin. Invest. 111, 3-10.

Qian, Y., Guan, T., Huang, M., Cao, L., Li, Y., Cheng, H., et al. (2012). Neuroprotection by the soy isoflavone, genistein, via inhibition of mitochondria-dependent apoptosis pathways and reactive oxygen inducedNF-kappaB activation in a cerebral ischemia mouse model. Neurochem. Int. 60, 759-767. doi: 10.1016/j.neuint.2012.03.011

Quik, M., Perez, X. A., and Bordia, T. (2012). Nicotine as a potential neuroprotective agent for Parkinson's disease. Mov. Disord. 27, 947-957. doi: $10.1002 / \mathrm{mds} .25028$

Ramanathan, S., Archunan, G., Sivakumar, M., Tamil Selvan, S., Fred, A. L., Kumar, S., et al. (2018). Theranostic applications of nanoparticles in neurodegenerative disorders. Intern. J. Nanomed. 13, 5561-5576. doi: 10.2147/IJN.S1 49022

Ratheesh, G., Tian, L., Venugopal, J. R., Ezhilarasu, H., Sadiq, A., Fan, T.-P., et al. (2017). Role of medicinal plants in neurodegenerative diseases. Biomanufactur. Rev. 2:2.

Re, F., Gregori, M., and Masserini, M. (2012). Nanotechnology for neurodegenerative disorders. Maturitas 73, 45-51. doi: 10.1016/j.maturitas. 2011.12.015

Rehman, M. U., Wali, A. F., Ahmad, A., Shakeel, S., Rasool, S., Ali, R., et al. (2019). Neuroprotective strategies for neurological disorders by natural products: an update. Curr. Neuropharmacol. 17, 247-267. doi: 10.2174/ 1570159X16666180911124605

Rocca, W. A. (2018). The burden of Parkinson's disease: a worldwide perspective. Lancet Neurol. 17, 928-929. doi: 10.1016/s1474-4422(18)30355-7

Rogan, S., and Lippa, C. F. (2002). Alzheimer's disease and other dementias: a review. Am. J. Alzheimer Dis. Other Dement. 17, 11-17.

Roney, C., Kulkarni, P., Arora, V., Antich, P., Bonte, F., Wu, A., et al. (2005). Targeted nanoparticles for drug delivery through the blood-brain barrier for Alzheimer's disease. J. Control. Release 108, 193-214.

Ross, C. A., Aylward, E. H., Wild, E. J., Langbehn, D. R., Long, J. D., Warner, J. H., et al. (2014). Huntington disease: natural history, biomarkers and prospects for therapeutics. Nat. Rev. Neurol. 10:204. doi: 10.1038/nrneurol.2014.24

Samudre, S., Tekade, A., Thorve, K., Jamodkar, A., Parashar, G., and Chaudhari, N. J. D. D. L. (2015). Xanthan gum coated mucoadhesive liposomes for efficient nose to brain delivery of curcumin. Drug Deliv. Lett. 5, 201-207. doi: 10.2174/ 2210303106666160120215857

Sancini, G., Gregori, M., Salvati, E., Cambianica, I., Re, F., Ornaghi, F., et al. (2013). Functionalization with TAT-peptide enhances blood-brain barrier crossing in vitro of nanoliposomes carrying a curcumin-derivative to bind amyloid- $\beta$ peptide. Science 4, 1-8.

Sandhir, R., Yadav, A., Mehrotra, A., Sunkaria, A., Singh, A., and Sharma, S. J. N. M. (2014). Curcumin nanoparticles attenuate neurochemical and neurobehavioral deficits in experimental model of Huntington's disease. Neuromol. Med. 16, 106-118. doi: 10.1007/s12017-013-8261-y

Sarko, D. K., and Mckinney, C. E. (2017). Exosomes: origins and therapeutic potential for neurodegenerative disease. Front. Neurosci. 11:82. doi: 10.3389/ fnins.2017.00082

Scalfari, A., Neuhaus, A., Daumer, M., Muraro, P. A., and Ebers, G. C. (2014). Onset of secondary progressive phase and long-term evolution of multiple sclerosis. J. Neurol. Neurosurg. Psychiatr. 85, 67-75. doi: 10.1136/jnnp-2012-304333

Schrag, A., Horsfall, L., Walters, K., Noyce, A., and Petersen, I. (2015). Prediagnostic presentations of Parkinson's disease in primary care: a casecontrol study. Lancet Neurol. 14, 57-64. doi: 10.1016/s1474-4422(14)70287-x

Shao-Ling, W., Ying, L., Ying, W., Yan-Feng, C., Li-Xin, N., Song-Tao, L., et al. (2009). Curcumin, a potential inhibitor of up-regulation of TNF-alpha and IL6 induced by palmitate in 3T3-L1 adipocytes through NF-kappaB and JNK pathway. Biomed. Environ. Sci. 22, 32-39. doi: 10.1016/S0895-3988(09)60019-2

Shea, T. B., Ortiz, D., Nicolosi, R. J., Kumar, R., and Watterson, A. C. (2005). Nanosphere-mediated delivery of vitamin E increases its efficacy against oxidative stress resulting from exposure to amyloid beta. J. Alzheimer Dis. 7, 297-301. doi: 10.3233/jad-2005-7405

Shi, C., Liu, J., Wu, F., and Yew, D. T. (2010). Ginkgo biloba extract in Alzheimer's disease: from action mechanisms to medical practice. Intern. J. Mol. Sci. 11, 107-123. doi: 10.3390/ijms11010107 
Shinji, S., Yasukazu, T., Hatsue, W., Kazuo, K., Machiko, I., and Naoki, M. J. (2011). Analysis of brain cell activation by nanosized particles of Ginkgo biloba extract. Acad. J. 3, 28-33.

Singh, N. A., Mandal, A. K. A., and Khan, Z. A. (2016). Potential neuroprotective properties of epigallocatechin-3-gallate (EGCG). Nutr. J. 15, 60-60.

Smith, A., Giunta, B., Bickford, P. C., Fountain, M., Tan, J., and Shytle, R. D. (2010). Nanolipidic particles improve the bioavailability and $\alpha$-secretase inducing ability of epigallocatechin-3-gallate (EGCG) for the treatment of Alzheimer's disease. Int. J. Pharm. 389, 207-212. doi: 10.1016/j.ijpharm.2010. 01.012

Stoffels, J. M., De Jonge, J. C., Stancic, M., Nomden, A., Van Strien, M. E., Ma, D., et al. (2013). Fibronectin aggregation in multiple sclerosis lesions impairs remyelination. Brain 136, 116-131. doi: 10.1093/brain/aws313

Strathearn, K. E., Yousef, G. G., Grace, M. H., Roy, S. L., Tambe, M. A., Ferruzzi, M. G., et al. (2014). Neuroprotective effects of anthocyanin- and proanthocyanidin-rich extracts in cellular models of Parkinson $\times$ s disease. Brain Res. 1555, 60-77. doi: 10.1016/j.brainres.2014.01.047

Sun, D., Li, N., Zhang, W., Zhao, Z., Mou, Z., Huang, D., et al. (2016). Design of PLGA-functionalized quercetin nanoparticles for potential use in Alzheimer's disease. Coll. Surf. B Biointerf. 148, 116-129. doi: 10.1016/j.colsurfb.2016.08. 052

Sun, J., Wei, C., Liu, Y., Xie, W., Xu, M., Zhou, H., et al. (2019). Progressive release of mesoporous nano-selenium delivery system for the multi-channel synergistic treatment of Alzheimer's disease. Biomaterials 197, 417-431. doi: 10.1016/j.biomaterials.2018.12.027

Szwajgier, D., Borowiec, K., and Pustelniak, K. (2017). The neuroprotective effects of phenolic acids: molecular mechanism of action. Nutrients 9:477. doi: 10 . 3390/nu9050477

Taghipour, Y. D., Hajialyani, M., Naseri, R., Hesari, M., Mohammadi, P., Stefanucci, A., et al. (2019). Nanoformulations of natural products for management of metabolic syndrome. Intern. J. Nanomed. 14:5303. doi: 10.2147/IJN.S213831

Taylor, M., Moore, S., Mourtas, S., Niarakis, A., Re, F., Zona, C., et al. (2011). Effect of curcumin-associated and lipid ligand-functionalized nanoliposomes on aggregation of the Alzheimer's A $\beta$ peptide. Nanomed. Nanotechnol. Biol. Med. 7, 541-550. doi: 10.1016/j.nano.2011.06.015

Tellone, E., Galtieri, A., Russo, A., and Ficarra, S. (2017). Protective effects of the caffeine against neurodegenerative diseases. Curr. Med. Chem. 26, 5137-5151. doi: 10.2174/0929867324666171009104040

Tiwari, S. K., Agarwal, S., Seth, B., Yadav, A., Nair, S., Bhatnagar, P., et al. (2013). Curcumin-loaded nanoparticles potently induce adult neurogenesis and reverse cognitive deficits in Alzheimer's disease model via canonical Wnt $/ \beta$-catenin pathway. ACS Nano 8, 76-103. doi: 10.1021/nn405077y

Tizabi, Y., Hurley, L. L., Qualls, Z., and Akinfiresoye, L. (2014). Relevance of the anti-inflammatory properties of curcumin in neurodegenerative diseases and depression. Molecules 19, 20864-20879. doi: 10.3390/molecules1912 20864

Tonda-Turo, C., Origlia, N., Mattu, C., Accorroni, A., and Chiono, V. (2018). Current limitations in the Treatment of Parkinson's and Alzheimer's diseases: state-of-the-art and future perspective of polymeric carriers. Curr. Med. Chem. 25, 5755-5771. doi: 10.2174/0929867325666180221125759

Trombino, S., Cassano, R., Ferrarelli, T., Barone, E., Picci, N., Mancuso, C. J. C., et al. (2013). Trans-ferulic acid-based solid lipid nanoparticles and their antioxidant effect in rat brain microsomes. Coll. Surf. B Biointerf. 109, 273-279. doi: 10.1016/j.colsurfb.2013.04.005

Vedagiri, A., and Thangarajan, S. (2016). Mitigating effect of chrysin loaded solid lipid nanoparticles against Amyloid $\beta 25-35$ induced oxidative stress in rat hippocampal region: An efficient formulation approach for Alzheimer's disease. Neuropeptides 58, 111-125. doi: 10.1016/j.npep.2016.03.002

Vital, M. J. S., Carneiro, A. L. B., e Silva, L. F. R., Amorim, R. C. N., Camargo, M. R. M., and Pohlit, A. M. (2015). Chemical Composition, Ethnopharmacology and Biological Activity of Geissospermum Allemão Species (Apocynaceae Juss.), Vol. 8. Brazil: Fundação Oswaldo Cruz. Farmanguinhos. Núcleo de Gestão em Biodiversidade e Saúde.

Vroegrijk, I. O., Van Diepen, J. A., Van Den Berg, S., Westbroek, I., Keizer, H., Gambelli, L., et al. (2011). Pomegranate seed oil, a rich source of punicic acid, prevents diet-induced obesity and insulin resistance in mice. Food Chem. Toxicol. 49, 1426-1430. doi: 10.1016/j.fct.2011.03.037
Wang, B., Su, C. J., Liu, T. T., Zhou, Y., Feng, Y., Huang, Y., et al. (2018). The neuroprotection of low-dose morphine in cellular and animal models of Parkinson's disease through ameliorating endoplasmic reticulum (ER) stress and activating autophagy. Front. Mol. Neurosci. 11:120. doi: 10.3389/fnmol. 2018.00120

Wang, X., Li, G., Zhang, P., Li, W., and He, X. J. (2019). Surface engineering of resveratrol to improve neuro-protection and functional recovery after spinal cord injury in rat. J. Drug Deliv. Sci. Technol. 49, 89-96. doi: 10.1016/j.jddst. 2018.10.016

Wang, Z. H., Wang, Z. Y., Sun, C. S., Wang, C. Y., Jiang, T. Y., and Wang, S. L. J. B. (2010). Trimethylated chitosan-conjugated PLGA nanoparticles for the delivery of drugs to the brain. Biomaterials 31, 908-915. doi: 10.1016/j.biomaterials. 2009.09.104

Win-Shwe, T. T., and Fujimaki, H. (2011). Nanoparticles and neurotoxicity. Intern. J. Mol. Sci. 12, 6267-6280. doi: 10.3390/ijms12096267

World Health Organization (2006). Neurological Disorders: Public Health Challenges. (Geneva: World Health Organization).

World Health Organization (2018). The Top 10 Causes Of Death. Geneva: World Health Organization.

Xiang, C., Zhang, Y., Guo, W., and Liang, X. J. (2019). Biomimetic carbon nanotubes for neurological disease therapeutics as inherent medication. Acta Pharm. Sin. B 10, 239-248. doi: 10.1016/j.apsb.2019.11.003

Xiao, X.-Y., Zhu, Y.-X., Bu, J.-Y., Li, G.-W., Zhou, J.-H., and Zhou, S. P. (2016). Evaluation of neuroprotective effect of thymoquinone nanoformulation in the rodent cerebral ischemia-reperfusion model. Biomed. Res. Intern. 2016:2571060.

Xie, J., Shen, Z., Anraku, Y., Kataoka, K., and Chen, X. (2019). Nanomaterialbased blood-brain-barrier (BBB) crossing strategies. Biomaterials 224:119491. doi: 10.1016/j.biomaterials.2019.119491

Yang, X., Zheng, T., Hong, H., Cai, N., Zhou, X., Sun, C., et al. (2018). Neuroprotective effects of Ginkgo biloba extract and Ginkgolide B against oxygen-glucose deprivation/reoxygenation and glucose injury in a new in vitro multicellular network model. Front. Med. 12:307. doi: 10.1007/s11684-017$0547-2$

Yasuda, T., and Mochizuki, H. (2010). The regulatory role of $\alpha$-synuclein and parkin in neuronal cell apoptosis; possible implications for the pathogenesis of Parkinson's disease. Apoptosis 15, 1312-1321. doi: 10.1007/s10495-010-0486-8

Yin, T., Yang, L., Liu, Y., Zhou, X., Sun, J., and Liu, J. (2015). Sialic acid (SA)-modified selenium nanoparticles coated with a high blood-brain barrier permeability peptide-B6 peptide for potential use in Alzheimer's disease. Acta Biomater. 25, 172-183. doi: 10.1016/j.actbio.2015.06.035

Yu, Y., Hayashi, S., Cai, X., Fang, C., Shi, W., Tsutsui, H., et al. (2014). Pu-erh tea extract induces the degradation of FET family proteins involved in the pathogenesis of amyotrophic lateral sclerosis. Biomed. Res. Intern. 2014:254680. doi: $10.1155 / 2014 / 254680$

Yusuf, M., Khan, M., Khan, R. A., and Ahmed, B. J. (2013). Preparation, characterization, in vivo and biochemical evaluation of brain targeted Piperine solid lipid nanoparticles in an experimentally induced Alzheimer's disease model. J. Drug Target. 21, 300-311. doi: 10.3109/1061186x.2012.747529

Zarei, S., Carr, K., Reiley, L., Diaz, K., Guerra, O., Altamirano, P. F., et al. (2015). A comprehensive review of amyotrophic lateral sclerosis. Surg. Neurol. Intern. 6:171. doi: 10.4103/2152-7806.169561

Zhang, C., Browne, A., Child, D., and Tanzi, R. E. (2010). Curcumin decreases amyloid- $\beta$ peptide levels by attenuating the maturation of amyloid- $\beta$ precursor protein. J. Biol. Chem. 285, 28472-28480. doi: 10.1074/jbc.M110.133520

Zhang, C., Chen, J., Feng, C., Shao, X., Liu, Q., Zhang, Q., et al. (2014). Intranasal nanoparticles of basic fibroblast growth factor for brain delivery to treat Alzheimer's disease. Intern. J. Pharm. 461, 192-202. doi: 10.1016/j.ijpharm. 2013.11.049

Zhang, J., Zhou, X., Yu, Q., Yang, L., Sun, D., Zhou, Y., et al. (2014). Epigallocatechin-3-gallate (EGCG)-stabilized selenium nanoparticles coated with Tet-1 peptide to reduce amyloid- $\beta$ aggregation and cytotoxicity. ACS Appl. Mater. Interf. 6, 8475-8487. doi: 10.1021/am501341u

Zhang, M., Zang, X., Wang, M., Li, Z., Qiao, M., Hu, H., et al. (2019). Exosomebased nanocarriers as bio-inspired and versatile vehicles for drug delivery: recent advances and challenges. J. Mater. Chem. B 7, 2421-2433. doi: 10.1039/ c9tb00170k 
Zhao, G., Dong, X., and Sun, Y. (2018). Self-assembled curcumin-poly (carboxybetaine methacrylate) conjugates: potent nano-inhibitors against amyloid $\beta$-protein fibrillogenesis and cytotoxicity. Langmuir 35, 1846-1857. doi: 10.1021/acs.langmuir.8b01921

Zheng, W., Wei, M., Li, S., and Le, W. (2016). Nanomaterial-modulated autophagy: underlying mechanisms and functional consequences. Nanomedicine 11, 14171430. doi: 10.2217/nnm-2016-0040

Zhou, X., Sun, J., Yin, T., Le, F., Yang, L., Liu, Y., et al. (2015). Enantiomers of cysteine-modified SeNPs (d/l SeNPs) as inhibitors of metal-induced A $\beta$ aggregation in Alzheimer's disease. J. Mater. Chem. B 3, 7764-7774. doi: 10. 1039/c5tb00731c
Conflict of Interest: The authors declare that the research was conducted in the absence of any commercial or financial relationships that could be construed as a potential conflict of interest.

Copyright (c) 2020 Moradi, Momtaz, Bayrami, Farzaei and Abdollahi. This is an open-access article distributed under the terms of the Creative Commons Attribution License (CC BY). The use, distribution or reproduction in other forums is permitted, provided the original author(s) and the copyright owner(s) are credited and that the original publication in this journal is cited, in accordance with accepted academic practice. No use, distribution or reproduction is permitted which does not comply with these terms. 